\title{
ONE- AND TWO-EQUATION MODELS FOR CANOPY TURBULENCE
}

\author{
GABRIEL G. KATUL ${ }^{1,2, *}$, LARRY MAHRT ${ }^{3}$, DAVIDE POGGI ${ }^{1,2,4}$ and \\ CHRISTOPHE SANZ ${ }^{5}$ \\ ${ }^{1}$ Nicholas School of the Environment and Earth Sciences, Box 90328, Duke University, Durham, \\ NC 27708-0328, U.S.A.; ${ }^{2}$ Department of Civil and Environmental Engineering, Pratt School of \\ Engineering, Duke University, Durham, NC 27709, U.S.A.; ${ }^{3}$ College of Oceanic \& Atmospheric \\ Sciences, Oregon State University, 104 Ocean Admin Bldg, Corvallis, OR 97331-5503, U.S.A.; \\ ${ }^{4}$ Dipartimento di Idraulica, Trasporti ed Infrastrutture Civili, Politecnico di Torino, Torino, \\ Italy; ${ }^{5} 17$ Avenue du Temps Perdu, 95280 Jouy le Moutier, France
}

(Received in final form 23 December 2003)

\begin{abstract}
The predictive skills of single- and two-equation (or $K-\varepsilon$ ) models to compute profiles of mean velocity $(U)$, turbulent kinetic energy $(K)$, and Reynolds stresses $\left(\overline{u^{\prime} w^{\prime}}\right)$ are compared against datasets collected in eight vegetation types and in a flume experiment. These datasets range in canopy height $\mathrm{h}$ from 0.12 to $23 \mathrm{~m}$, and range in leaf area index (LAI) from 2 to $10 \mathrm{~m}^{2} \mathrm{~m}^{-2}$. We found that for all datasets and for both closure models, measured and modelled $U, K$, and $\overline{u^{\prime} w^{\prime}}$ agree well when the mixing length $\left(l_{\mathrm{m}}\right)$ is a priori specified. In fact, the root-mean squared error between measured and modelled $U, K$, and $\overline{u^{\prime} w^{\prime}}$ is no worse than published values for second- and third-order closure approaches. Within the context of onedimensional modelling, there is no clear advantage to including a turbulent kinetic dissipation rate $(\varepsilon)$ budget when $l_{\mathrm{m}}$ can be specified instead. The broader implication is that the added complexity introduced by the $\varepsilon$ budget in $K-\varepsilon$ models need not translate into improved predictive skills of $U, K$, and $\overline{u^{\prime} w^{\prime}}$ profiles when compared to single-equation models.
\end{abstract}

Keywords: Canopy turbulence, Closure models, K-epsilon models, Two-equation models.

\section{Introduction}

Simplified mathematical models that faithfully mimic the behaviour of canopy turbulence, yet are computationally efficient, are receiving attention in numerous fields such as hydrology, ecology, climate system modelling and various engineering branches (Raupach, 1989a, 1991; Lumley, 1992; Finnigan, 2000). Common to all these fields is the need to compute a system-state over large spatial and temporal scales. However, the state evolution equations describe complex turbulent transport processes rich in variability at numerous scales (Lumley, 1992; Raupach et al., 1992; Raupach and Finnigan, 1997; Albertson et al., 2001; Horn et al., 2001; Katul et al., 2001a; Nathan et al., 2002).

*E-mail: gaby@duke.edu

Boundary-Layer Meteorology 113: 81-109, 2004.

(C) 2004 Kluwer Academic Publishers. Printed in the Netherlands. 
The behaviour of canopy turbulence is far too complex to admit a unique parameterization across a broad range of flow types and boundary conditions. Required outputs from canopy turbulence models include, at a minimum, mean flow $(U)$, turbulent kinetic energy $(K)$, some partitioning of $K$ among its three components, and Reynolds stresses (Raupach, 1989a, b; Katul and Albertson, 1999; Lai et al., 2000a, b; Katul et al., 2001b; Lai et al., 2002). Identifying the minimum turbulence closure model necessary to efficiently simulate the mean flow and measures of second-order flow statistics is a logical research question (Wilson et al., 1998). In principle, second-order closure models can predict such flow statistics (Meyers and Paw U, 1986, 1987; Meyers, 1987; Wilson, 1988; Paw and Meyers, 1989; Katul and Albertson, 1998, 1999; Ayotte et al., 1999; Katul and Chang, 1999). However, they are computationally expensive and require complex numerical algorithms for three-dimensional transport problems (especially if multiple scalar species must be treated). On the other hand, first-order closure models may well reproduce mean velocity (Wilson et al., 1998; Pinard and Wilson, 2001) but cannot provide second-order statistics, the latter being needed in almost all problems relevant to scalar transport. A logical choice is a 1.5-closure model in which a budget equation for $K$ (or one-equation models) must be explicitly considered. In fact, such models, known as two-equation models or $K-\varepsilon$ models are among the most popular computational models in engineering applications (Bradshaw et al., 1991; Launder, 1996; Speziale, 1996; Pope, 2000) and more recently in atmospheric flows over complex terrain (Castro et al., 2003). However, these models have received limited attention in canopy turbulence (Sanz, 2003). A handful of $K-\varepsilon$ models have been investigated for wind-tunnel canopy flows (Green, 1992; Kobayashi et al., 1994; Liu et al., 1996), yet their generality and applicability to complex canopy morphology commonly encountered in the canopy sublayer (CSL) remain uncertain and is the subject of this investigation.

We explore different classes of $K-\varepsilon$ models (and simplifications to them) for a broad range of canopy morphologies. These morphological differences range from controlled experiments in a flume, to a constant leaf area density of a rice canopy, to moderately variable leaf area density of corn, to pine and deciduous forests with highly erratic leaf area densities.

\section{Two-Equation $(K-\varepsilon)$ Modelling}

The simplified equations for a neutrally stratified, planar homogeneous, steady state, and high Reynolds number flow within a dense and extensive canopy are considered. With these idealizations, and following standard $K-\varepsilon$ closure assumptions, the basic transport equations for the mean momentum, turbulent kinetic energy $(K)$, and turbulent kinetic energy dissipation rate $(\varepsilon)$, 
in the absence of a mean pressure gradient, reduce to (Warsi, 1992; Pope, 2000; Sanz, 2003):

mean momentum:

$$
0=\frac{d}{d z}\left(v_{t} \frac{d U}{d z}\right)+S_{U}
$$

turbulent kinetic energy $(K)$ :

$$
0=\frac{d}{d z}\left(\frac{v_{t}}{S c_{K}} \frac{d K}{d z}\right)+v_{t}\left(\frac{d U}{d z}\right)^{2}-\varepsilon+S_{K}
$$

turbulent kinetic energy dissipation rate $(\varepsilon)$ :

$$
0=\frac{d}{d z}\left(\frac{v_{t}}{S c_{\varepsilon}} \frac{d \varepsilon}{d z}\right)+C_{\varepsilon 1} C_{\mu} K\left(\frac{d U}{d z}\right)^{2}-C_{\varepsilon 2} \frac{\varepsilon^{2}}{K}+S_{\varepsilon}
$$

where $z$ is the height above the ground (or forest floor) surface, $U$ is the mean longitudinal velocity, $v_{t}$ is the turbulent viscosity, $S_{U}$ is the momentum extraction rate by the canopy elements due to both form and viscous drag, $S_{K}$ is the net turbulent kinetic energy loss rate due to the canopy, $S_{\varepsilon}$ is analogous to $S_{K}$ but for the dissipation rate equation, $C_{\varepsilon 1}, C_{\varepsilon 2}$, and $C_{\mu}$ are closure constants, and $S c_{K}$ and $S c_{\varepsilon}$ are the turbulent Schmidt numbers for K and $\varepsilon$, usually set at 1.0 and 1.3, respectively (Speziale, 1996) for laboratory studies. For atmospheric flow studies, $S c_{\varepsilon}$ is usually larger than 1.3 (and is discussed later).

Unless otherwise stated, all flow variables are time and spatially averaged (Raupach and Shaw, 1982). To solve for $U, K$, and $\varepsilon$, parameterizations for $v_{t}, S_{U}, S_{K}$, and $S_{\varepsilon}$ as well as appropriate boundary conditions are needed, and discussed next.

\subsection{MODEL FOR $v_{t}$}

Standard models for $v_{t}$ fall in one of the two categories:

$$
v_{t}=\left\{\begin{array}{l}
v_{t}^{(i)}=C_{\mu}^{1 / 4} l_{m} K^{1 / 2}, \\
\text { or } \\
v_{t}^{(i i)}=C_{\mu} \frac{K^{2}}{\varepsilon},
\end{array}\right.
$$

where $l_{\mathrm{m}}$ is a mixing length. In standard $K-\varepsilon$ models, $v_{t}=v_{t}^{(i i)}$ because such a formulation eliminates the need for an additional variable (i.e., $l_{\mathrm{m}}$ ) thereby resulting in a self-contained parsimonious model (Bradshaw et al., 1991; Launder, 1996). On the other hand, closure formulations for $\varepsilon$ in the CSL are more uncertain than their $K$-equation counterpart (Wilson et al., 1998). Hence, linking $v_{t}$ to the most uncertain modelled variable (i.e., $\varepsilon$ ) may produce 
greater uncertainty and reduced model skill, a hypothesis that will also be investigated here. Furthermore, recent experiments suggest that $l_{\mathrm{m}}$ within the canopy is locally independent of $z$ (Liu et al., 1996; Massman and Weil, 1999; Poggi et al., 2004a) at least for $z<0.7 h$, where $h$ is the canopy height. Above the canopy $(z>h), l_{\mathrm{m}}$ is well described by the classical rough-wall boundarylayer formulation. In short, a simplified and satisfactory model for $l_{\mathrm{m}}$ in dense canopies, in the absence of stability, is given by

$$
l_{\mathrm{m}}=\left\{\begin{array}{l}
\alpha h ; z / h<1, \\
k_{v}(z-d) ; z / h>1 .
\end{array}\right.
$$

As discussed in Poggi et al. (2004a), this model can account for known properties of canopy turbulence mixing including the generation of von Karman streets; in the above $k_{v}=0.4$ is the von Karman constant, and $d$ $(\approx 2 / 3 h$ in dense canopies) is the zero-plane displacement height. This model is conceptually similar to earlier constant length models within the CSL ( $\mathrm{Li}$ et al., 1985; Massman and Weil, 1999) though not identical. One limitation to this model is that $l_{\mathrm{m}}$ is assumed to be finite near the ground, which is unrealistic. However, as discussed by Katul and Chang (1999), the impact of this assumption affects a limited region, about $0.05 h$ for dense canopies. We are well aware that a length scale specification cannot be universal across all flow regimes. For example, separation or recirculation may occur, especially for airflow within canopies on complex topography thereby limiting the generality of the modelled eddy viscosity. Furthermore, it is likely that local stability effects alter $l_{\mathrm{m}}$ within the canopy (Mahrt et al., 2000).

Given that $l_{\mathrm{m}}$ reflects known bulk characteristics of canopy eddies (Raupach et al., 1996; Katul et al., 1998; Finnigan, 2000), and noting the large uncertainty in the $\varepsilon$ models, $v_{t}=v_{t}^{(i)}$ appears to be rational. We further investigate this point later.

We determine $\alpha$ by noting that $l_{\mathrm{m}}$ is continuous at $z / h=1$ resulting in $\alpha=k_{v} / 3$ for $d=(2 / 3) h$. This estimate of $\alpha$ is in excellent agreement with flume experiment estimates reported for dense rods in a flume having a comparable $d$ (Poggi et al., 2004a).

\subsection{MODEL FOR $S_{u}, S_{K}$, AND $S_{\varepsilon}$}

Among the primary reasons why $K-\varepsilon$ models have not received much attention in CSL turbulence applications is attributed to the difficulty in modelling the effects of the canopy on the flow statistics by $S_{u}, S_{K}$, and $S_{\varepsilon}$.

The standard model for $S_{u}$ is to neglect viscous drag relative to form drag, thereby resulting in 


$$
S_{u}=-C_{d} a U^{2},
$$

where $C_{d}$ is the drag coefficient $(\approx 0.1-0.3$ for most vegetation), and $a$ is the leaf area density $\left(\mathrm{m}^{2} \mathrm{~m}^{-3}\right)$, which can vary appreciably with $z$ (especially in forested systems). For simplicity, we define $C_{z}=C_{d} \times a$ as the effective drag on the flow.

The term $S_{K}$ arises because vegetation elements break the mean flow motion and generate wake turbulence $\left(\approx C_{z} U^{3}\right)$. However, such wakes dissipate rapidly (Raupach and Shaw, 1982) often leading to a 'short-circuiting' of the Kolmogorov cascade (Kaimal and Finnigan, 1994; Poggi et al., 2004a). The canonical form for $S_{K}$, reflecting such mechanisms, is given by (Sanz, 2003):

$$
S_{K}=C_{z}\left(\beta_{p} U^{3}-\beta_{d} U K\right),
$$

where $\beta_{p}(\approx 1.0)$ is the fraction of mean flow kinetic energy converted to wake-generated $K$ by canopy drag (i.e., a source term in the $K$ budget), and $\beta_{d}(\approx 1.0-5.0)$ is the fraction of $K$ dissipated by short-circuiting of the cascade (i.e., a sink term in the $K$ budget).

The primary weakness of $K-\varepsilon$ approaches is $S_{\varepsilon}$ (Wilson et al., 1998), the least understood term in Equations (1) to (3). Over the last decade, various models have already been proposed for $S_{\varepsilon}$ and they take on one of two forms:

$$
S_{\varepsilon}=\left\{\begin{array}{l}
S_{\varepsilon}^{(i)}=C_{\varepsilon 4} \frac{\varepsilon}{K} S_{K}, \\
\text { or } \\
S_{\varepsilon}^{(i i)}=C_{z}\left[C_{\varepsilon 4} \beta_{p} \frac{\varepsilon}{K} U^{3}-C_{\varepsilon 5} \beta_{d} U \varepsilon\right],
\end{array}\right.
$$

where $C_{\varepsilon 4}$ and $C_{\varepsilon 5}$ are closure constants (see Table I); note, when $C_{\varepsilon 4}=C_{\varepsilon 5}$, the two formulations become identical (i.e., $S_{\varepsilon}^{(i)}=S_{\varepsilon}^{(i i)}$ ). The formulation for $S_{\varepsilon}^{(i)}$ is based on standard dimensional analysis common to all $K-\varepsilon$ approaches. The second formulation came about following a wind-tunnel study that demonstrated that $S_{\varepsilon}^{(i)}$ did not reproduce well-measured diffusivity for a laboratory 'model' forest (Liu et al., 1996). These authors then proposed $S_{\varepsilon}^{(i i)}$, which is similar to the original formulation put forth by others (Green, 1992) but differs in the magnitude of $C_{\varepsilon 5}$ (i.e., $C_{\varepsilon 4} \neq C_{\varepsilon 5}$ ). Upon replacing Equations (4)-(7) in Equations (1)-(3), it is possible to solve for $U, K$, and $\varepsilon$ if appropriate upper and lower boundary conditions are specified. Table I summarizes all the closure constants.

\subsection{BOUNDARY CONDITIONS}

The generic boundary conditions used here assume that well above the canopy (i.e., in the atmospheric surface layer, ASL), the flow statistics approach Monin and Obukhov similarity theory relationships for a planar 
TABLE I

Closure constants in $K-\varepsilon$ and $K-U$ models for all canopies.

\begin{tabular}{|c|c|c|}
\hline $\begin{array}{l}\text { Closure } \\
\text { constant }\end{array}$ & Value & Reference \\
\hline$S c_{K}$ & 1.0 & Standard $K-\varepsilon$ closure constants (Launder and Spalding, \\
\hline$S c_{\varepsilon}$ & $1.88(1.3)$ & 1974) that have been used for numerous flow types \\
\hline$C_{\mu}$ & $0.03(0.09)$ & including canopy turbulence by Liu et al. (1996), Green \\
\hline$C_{\varepsilon 1}$ & 1.44 & (1992), and Kobayashi et al. (1994). The standard \\
\hline$C_{\varepsilon 2}$ & 1.92 & $C_{\mu}=0.09$ is revised to 0.03 so that $v_{t}$ matches its ASL \\
\hline$C_{\varepsilon 4}$ & $0.9(1.5)$ & $\begin{array}{l}\text { value. Also, } S c_{\varepsilon} \text { should be revised from its standard } \\
\text { laboratory value of } 1.3-1.92 \text { to account for the change in } \\
C_{\mu} \text {. For the flume experiments, the standard closure } \\
\text { constants (in brackets) are used }\end{array}$ \\
\hline$C_{\varepsilon 5}$ & $0.9(1.5)$ & $\beta_{p}, \beta_{d}$ are identical to several CSL experiments (Green, \\
\hline$\beta_{p}$ & 1.0 & 1992; Kobayashi et al., 1994; Liu et al., 1996). Green \\
\hline$\beta_{d}$ & $5.1(4.0)$ & $\begin{array}{l}\text { reported } C_{\varepsilon 5}=1.5 \text { for consistency with the Kolmogorov } \\
\text { relation (Sanz, 2003) and is used in all our calculations, } \\
\text { while others found that } C_{\varepsilon 5}=0.4 \text { produces a better match } \\
\text { to their wind-tunnel data (Liu et al., 1996) }\end{array}$ \\
\hline $\begin{array}{l}A_{u}, A_{v}, \\
\text { and } A_{w}\end{array}$ & $\begin{array}{l}2.4,2.1,1.25 \\
(1.5,1.35,1.2)\end{array}$ & $\begin{array}{l}\text { Standard ASL values (Garratt, 1992). They are boundary } \\
\text { conditions that uniquely determine } a_{3}=72.86 \text { (Katul and } \\
\text { Chang, 1999). These values are used for all canopies. The } \\
\text { values for the flume experiment are shown in brackets }\end{array}$ \\
\hline
\end{tabular}

For the $K-U$ model, only $\beta_{p}, \beta_{d}, a_{3}$, and $S c_{k}$ are used. Values in brackets are the standard values used for the flume measurements.

homogeneous, stationary, near-neutral flow (Brutsaert, 1982; Stull 1988; Garratt, 1992). At the forest floor or ground surface, constant gradients for $K$ and $\varepsilon$ are assumed while the gradient in $U$ is dependent on the local shear stress at the ground surface $\left.\overline{\left(u^{\prime} w^{\prime}\right.}(0)\right)$, which is negligible for dense canopies.

Hence, these boundary conditions translate to the following:

$$
z / h=0 ;\left\{\begin{array}{l}
\frac{d U}{d z} \approx \frac{\sqrt{-\overline{u^{\prime} w^{\prime}}(0)}}{k_{v} \Delta z}, \\
\frac{d K}{d z} \approx 0, \\
\frac{d \varepsilon}{d z} \approx 0,
\end{array}\right.
$$




$$
z / h>2 ;\left\{\begin{array}{l}
U=\frac{u_{*}}{k_{v}} \log \left[\frac{z-d}{z_{o}}\right], \\
K=\frac{1}{2}\left[A_{u}^{2}+A_{v}^{2}+A_{w}^{2}\right] u_{*}^{2} \text { (i.e., the flow approaches its neutral ASL state), } \\
\varepsilon=\frac{u_{*}^{3}}{k_{v}(z-d)},
\end{array}\right.
$$

where $z_{o}$ is the momentum roughness length for the canopy, which is about $0.08-0.18 \mathrm{~h}$ (Parlange and Brutsaert, 1989), $\Delta z$ is the computational grid node spacing (discussed later), and the similarity coefficients $A_{u}, A_{v}$, and $A_{w}$ are assumed constant independent of height and can be determined from their values for neutral ASL flows.

From standard ASL flow experiments (Garratt, 1992), these coefficients are approximately given by

$$
\begin{aligned}
& A_{u}=\frac{\sqrt{\overline{u^{\prime 2}}}}{u_{*}}=2.4, \\
& A_{v}=\frac{\sqrt{\overline{v^{\prime 2}}}}{u_{*}}=2.1, \\
& A_{w}=\frac{\sqrt{\overline{w^{\prime 2}}}}{u_{*}}=1.25,
\end{aligned}
$$

for a neutral ASL, where primed quantities denote departures from timeaveraged quantities (denoted by overbar), $u^{\prime}, v^{\prime}$, and $w^{\prime}$ are velocity excursions in the longitudinal, lateral, and vertical directions, respectively, and $u_{*}\left(=\sqrt[4]{{\overline{u^{\prime} w^{\prime}}}^{2}+{\overline{w^{\prime} v^{\prime}}}^{2}}\right)$ is the friction velocity at $z / h=1$. We use these values of $A_{u}, A_{v}$, and $A_{w}$ for all field experiments considered here. Furthermore, in dense canopies, it is reasonable to assume that $\overline{u^{\prime} w^{\prime}}(0) \approx 0$ (Katul and Albertson, 1998), which leads to a free slip condition at the forest floor. This approximation departs from the usual approximation of linking mean velocity just above the ground surface with the shear stress at the ground surface using a logarithmic profile, along with a specified roughness height at the ground surface (which is not known for all the datasets employed here). Finally, with these estimates of $A_{u}, A_{v}$, and $A_{w}$, the constant $C_{\mu}$ must be revised from its standard laboratory value $(=0.09)$ to reflect differences between $A_{u}$ and $A_{v}$ in field and laboratory experiments. Matching $v_{t}$ to its neutral ASL value $\left(=k_{v}(z-d) u_{*}\right)$, we obtain (Sanz, 2003)

$$
C_{\mu}=\frac{1}{\left(\frac{1}{2}\left[A_{u}^{2}+A_{v}^{2}+A_{w}^{2}\right]\right)^{2}} \approx 0.03 .
$$

The corresponding adjustment for $S c_{\varepsilon}$, assuming $C_{\varepsilon 1}$ and $C_{\varepsilon 2}$ are known (Table I), can be computed from 


$$
S c_{\varepsilon}=\frac{k_{v}^{2}}{\sqrt{C_{\mu}}\left(C_{\varepsilon 2}-C_{\varepsilon 1}\right)} \approx 1.92 .
$$

Hence, for the ASL field experiments, $S c_{\varepsilon}$ is revised from 1.3 (laboratory value) to 1.92 . The estimations of $\beta_{d}$ and $C_{\varepsilon 4}$ are based on the formulation in Sanz (2003) and are given by

$$
\begin{aligned}
& \beta_{d}=C_{\mu}^{1 / 2}\left(\frac{2}{\alpha^{\prime}}\right)^{2 / 3} \beta_{p}+\frac{3}{S c_{K}}, \\
& C_{\varepsilon 4}=S c_{K}\left(\frac{2}{S c_{\varepsilon}}-\frac{C_{\mu}^{1 / 2}}{6}\left(\frac{2}{\alpha^{\prime}}\right)^{2 / 3}\left(C_{\varepsilon 2}-C_{\varepsilon 1}\right)\right)=C_{\varepsilon 5},
\end{aligned}
$$

where $\alpha^{\prime}=0.05$ is a constant connected with the mixing length model discussed in Massman and Weil (1999). With these mathematical constraints, the only closure constants that require a priori specifications are $C_{\varepsilon 1}, C_{\varepsilon 2}$ and $\beta_{p}$ (see Table I).

\subsection{SiMPLIFICATIONS TO THE $K-\varepsilon$ MODELS: THE $K-U$ OR ONE-EQUATION MODEL}

Given the overall study objectives and given the uncertainty in the formulation of $S_{\varepsilon}$, a logical question to explore is whether the $\varepsilon$ budget is really contributing 'new information' to the solution of the $K$ budget. Notice that with a canonical mixing length scale specification, the $\varepsilon$ budget is strictly needed to compute one term in the $K$ budget. We explore a simpler model for $\varepsilon$ in which

$$
\varepsilon=\frac{q^{3}}{\lambda_{3}}
$$

where $\lambda_{3}=a_{3} l_{\mathrm{m}}, q=\sqrt{2 K}$ (Wilson and Shaw, 1977), and $a_{3}$ can be determined by the matching procedure described in Katul and Chang (1999) and which results in

$$
a_{3}=\frac{-A_{q}^{3}\left(A_{u}^{2}-A_{w}^{2}\right)}{A_{w}^{2}-\frac{A_{q}^{2}}{3}},
$$

where $A_{q}=\sqrt{A_{u}^{2}+A_{v}^{2}+A_{w}^{2}}$. Note that this approach departs from an earlier approach (e.g., Wilson et al., 1998) suggesting that $\varepsilon=\max \left(\varepsilon_{1}, \varepsilon_{2}\right)$, where

$$
\varepsilon_{1}=\frac{\left(c_{e} K\right)^{3 / 2}}{\lambda^{\prime}}, \quad \varepsilon_{2}=\beta_{d} C_{x} U K
$$

where $c_{e}$ is a closure constant, $\lambda^{\prime}$ is a length scale. Equation (8) is analogous to $\varepsilon_{1}$ and our formulation of $S_{K}$ already accounts for $\varepsilon_{2}$. Hence, when 
Equations (6) and (8) are combined with the $K$ budget in Equation (2), all the TKE dissipation pathways are considered. The resulting system of equations is given by

$$
\begin{aligned}
0= & \frac{d}{d z}\left(C_{\mu}^{1 / 4} l_{\mathrm{m}} K^{1 / 2} \frac{d U}{d z}\right)-C_{x} U^{2}, \\
0= & \frac{d}{d z}\left(C_{\mu}^{1 / 4} l_{\mathrm{m}} K^{1 / 2} \frac{d K}{d z}\right)+C_{\mu}^{1 / 4} l_{\mathrm{m}} K^{1 / 2}\left(\frac{d U}{d z}\right)^{2}-\frac{(2 K)^{3 / 2}}{a_{3} l_{\mathrm{m}}} \\
& +C_{x}\left(\beta_{p} U^{3}-\beta_{d} U K\right),
\end{aligned}
$$

and can be readily solved for $U$ and $K$ (with appropriate boundary conditions). We refer to the solution of this set of equations (i.e., Equations (9) and (10)) as the $K-U$ (or one-equation) model. The closure constants $\left(a_{3}, C_{\mu}, \beta_{p}\right.$, and $\beta_{d}$ ) are also summarized in Table I. Note that the $K-U$ model is independent of $S c_{\varepsilon}, C_{\varepsilon 1}, C_{\varepsilon 2}, C_{\varepsilon 4}$ and $C_{\varepsilon 5}$.

\section{Experiments}

The datasets used here include a flume experiment for a model canopy and CSL field experiments conducted in morphologically distinct canopies. The canopies include rice and corn crops, an even-aged Loblolly pine, Jack pine, and Scots pine forests, an aspen forest, a spruce forest, and an undisturbed oak-hickory-pine forest. Table II summarizes the key aerodynamic and morphological attributes for these canopies and Figures 1 to 9 present

\section{TABLE II}

Canopy morphology and aerodynamic properties of the vegetation types, where FL is the flume artificial canopy (rods), RI is the rice canopy, CO is the corn canopy, SP is the spruce

\begin{tabular}{|c|c|c|c|c|c|c|c|c|c|}
\hline Canopy & FL & RI & $\mathrm{CO}$ & SP & AS & JPI & SPI & LPI & HW \\
\hline $\mathrm{h}(\mathrm{m})$ & 0.12 & 0.72 & 2.2 & 10 & 10 & 15 & 20 & 16 & 22 \\
\hline $\begin{array}{l}\text { LAI }\left(\mathrm{m}^{2} \mathrm{~m}^{-2}\right) \text { or } \\
\text { Frontal area index }\end{array}$ & $\begin{array}{l}1072 \\
\text { rods } \mathrm{m}^{-2}\end{array}$ & 3.1 & 2.9 & 10.0 & 4.0 & 2.0 & 2.6 & 3.8 & 5.0 \\
\hline$C_{d}$ & Variable $^{\mathrm{a}}$ & 0.3 & 0.3 & 0.2 & 0.2 & 0.2 & 0.2 & 0.2 & 0.15 \\
\hline$z_{0} / h$ & 0.10 & 0.1 & 0.1 & 0.1 & 0.1 & 0.1 & 0.1 & 0.08 & 0.08 \\
\hline$d_{0} / h$ & 0.65 & $2 / 3$ & $2 / 3$ & $2 / 3$ & $2 / 3$ & $2 / 3$ & $2 / 3$ & $2 / 3$ & 0.8 \\
\hline
\end{tabular}
stand, AS is the aspen stand, JPI is the Jack pine stand, SPI is the Scots pine stand, LPI is the Loblolly pine stand, and HW is the hardwood forest.

${ }^{\mathrm{a}}$ See Poggi et al. (2004a). 

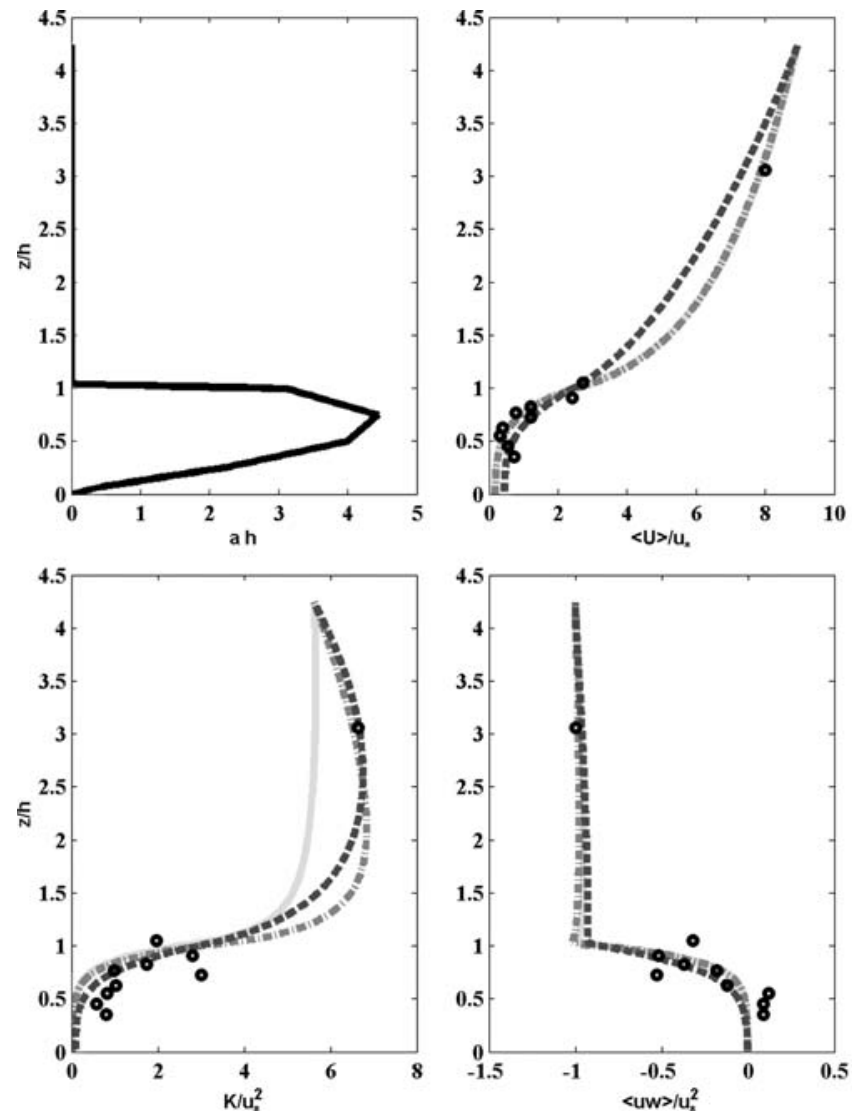

Figure 1. Comparison between measured (closed circles) and modelled flow statistics by $K-\varepsilon$ (solid line) with a prescribed length scale, the $K-U$ (dot-dashed line), and the $K-\varepsilon$ (dashed line) but using the standard $v_{t}=C_{\mu} \frac{K^{2}}{\varepsilon}$ for the rice canopy (RI), where $U$ is the mean wind speed, $K$ is the turbulent kinetic energy, and $\overline{u^{\prime} w^{\prime}}$ is the Reynolds stress. All the variables are normalized by canopy height $(h)$ and friction velocity $\left(u_{*}\right)$ at $z / h=1$. The measured leaf area density $(a)$, normalized by $h$ is also shown.

published velocity statistics and canopy leaf area density for these CSL experiments. The field sites, described next, were selected for three reasons:

(1) They span a broad range of leaf area density profiles (from nearly uniform to highly erratic), canopy heights $(0.72$ to $22 \mathrm{~m})$, LAI values (2.0 to $\left.10.0 \mathrm{~m}^{2} \mathrm{~m}^{-2}\right)$, and drag coefficients $(0.15$ to 0.3$)$.

(2) They include at least five levels of measurements.

(3) They are all nearly dense and extensive canopies.

For the purposes of our study, a dense canopy is defined as a canopy where $\frac{U}{u_{*}}$ at $z / h=1$ is nearly constant independent of roughness density (Raupach, 1994; Massman, 1997; Massman and Weil, 1999; Poggi et al., 

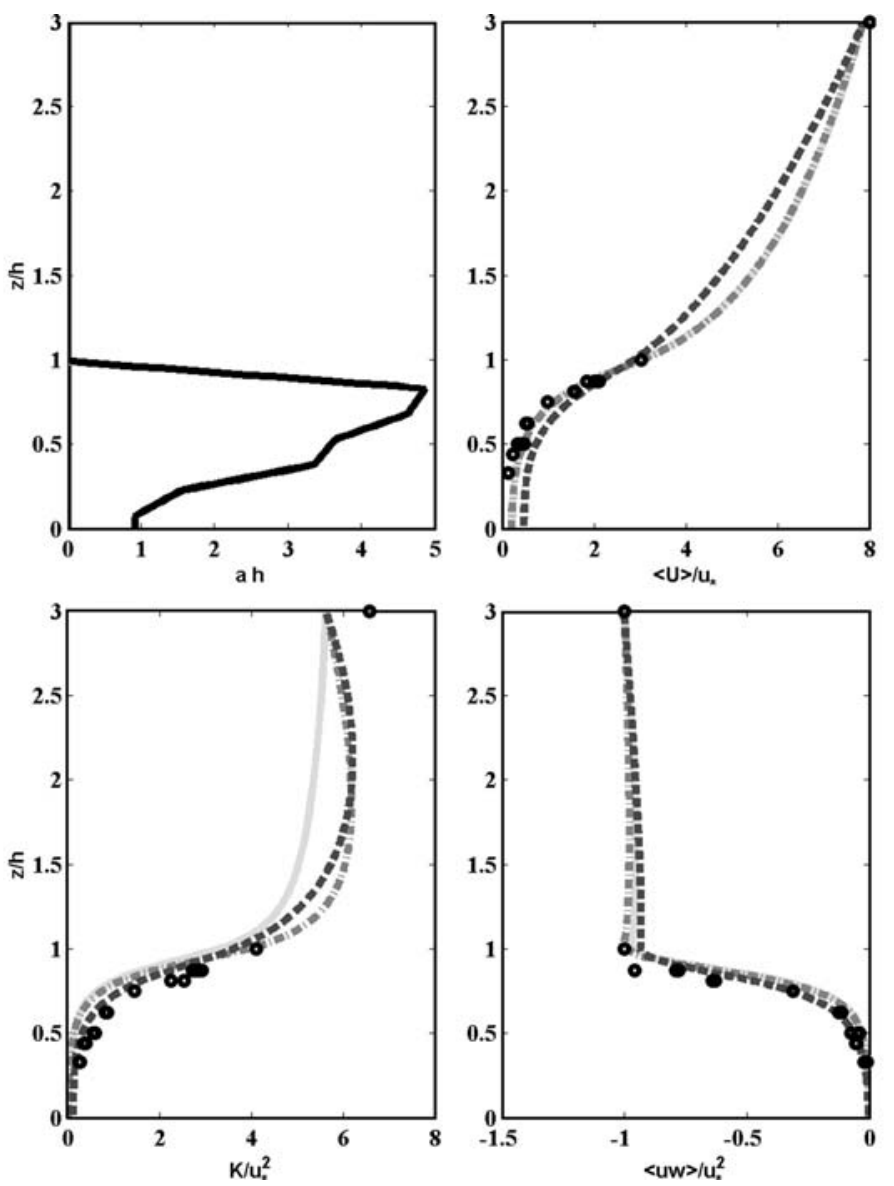

Figure 2. Same as Figure 1 but for the corn canopy (CO).

2004a). Sparse canopies pose an additional challenge, as the mixing length model in Equation (4b) is no longer valid; dispersive fluxes are another complication sparse canopies introduce. In dense canopies, dispersive fluxes are small and typically neglected; however, recent experimental evidence suggest that dispersive fluxes can be comparable in magnitude to the conventional Reynolds stresses in sparse canopies (e.g., Poggi et al., 2004b). It is for these reasons we chose to restrict our analysis and comparisons to dense canopies as a logical starting point for formulating and testing one- and twoequation models.

\subsection{THE RICE CANOPY}

The sonic anemometer set-up for the rice canopy is described elsewhere (Leuning et al., 2000; Katul et al., 2001b). In brief, the velocity measurements 

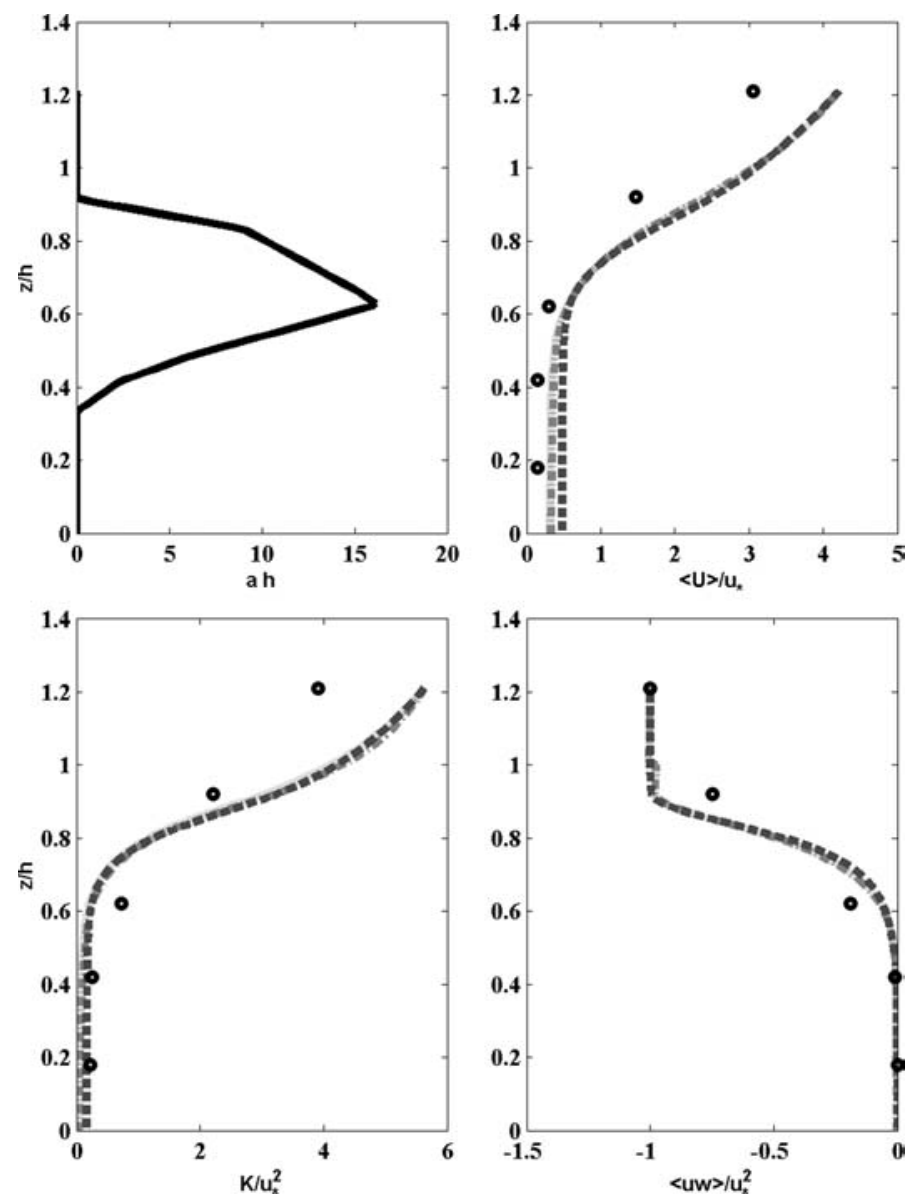

Figure 3. Same as Figure 1 but for the spruce canopy (SP).

were performed within and above a $0.72 \mathrm{~m}$ tall rice paddy at an agricultural station operated by Okayama University in Japan as part of the International Rice Experiment (IREX96). The leaf area density, measured by a canopy analyzer (LICOR, LAI-2000), is $3.1 \mathrm{~m}^{2} \mathrm{~m}^{-2}$. The measured $a$ (normalized by canopy height) is shown in Figure 1. A miniature three-dimensional sonic anemometer (Kaijo Denki, DAT 395, Tokyo, Japan) was positioned and displaced at multiple levels $(z / h=0.35,0.45,0.55,0.63,0.77,0.83,0.90,1.05)$ to measure velocity statistics within the canopy. For each of the eight levels, an ensemble of normalized turbulent statistics was formed and averaged for each stability class. In the ASL above the canopy, a Gill triaxial sonic anemometer (Solent 1021 R, Gill Instruments, Lymington, U.K.) was installed at $z / h=3.06$ to measure the velocity statistics in the ASL above the canopy. Only the neutral runs were employed here. 

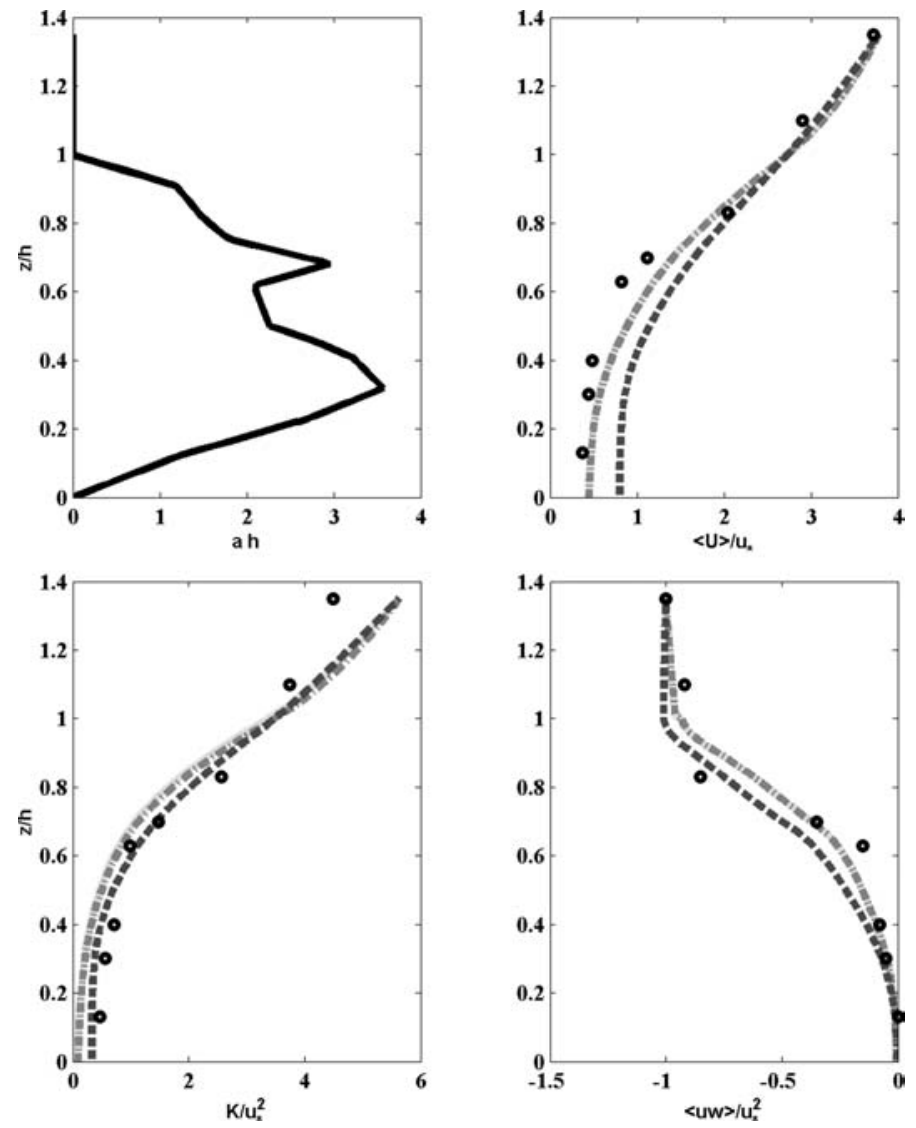

Figure 4. Same as Figure 1 but for the aspen canopy (AS).

\subsection{THE CORN CANOPY}

The experimental set-up is described (Wilson et al., 1982) and tabulated (Wilson, 1988) elsewhere. Briefly, the site is a $2.3 \mathrm{~m}$ tall mature corn canopy in Elora, Ontario, Canada. The first- and second-moment profiles were measured at $z / h=1.0,0.87,0.81,0.75,0.62,0.50,0.44$, and 0.33 using specially designed servo-controlled split film heat anemometers. The leaf area density was sampled just before the experiment at seven levels as shown in Figure 2; the sampling period for all flow statistics was $30 \mathrm{~min}$.

\subsection{THE SCOTS PINE CANOPY}

Measurements were made from 24 June to 15 July 1999 in and above a Scots pine forest, located $40 \mathrm{~km}$ south-west of the village of Zotino in central Siberia. A more detailed description of the site characteristics can be found 

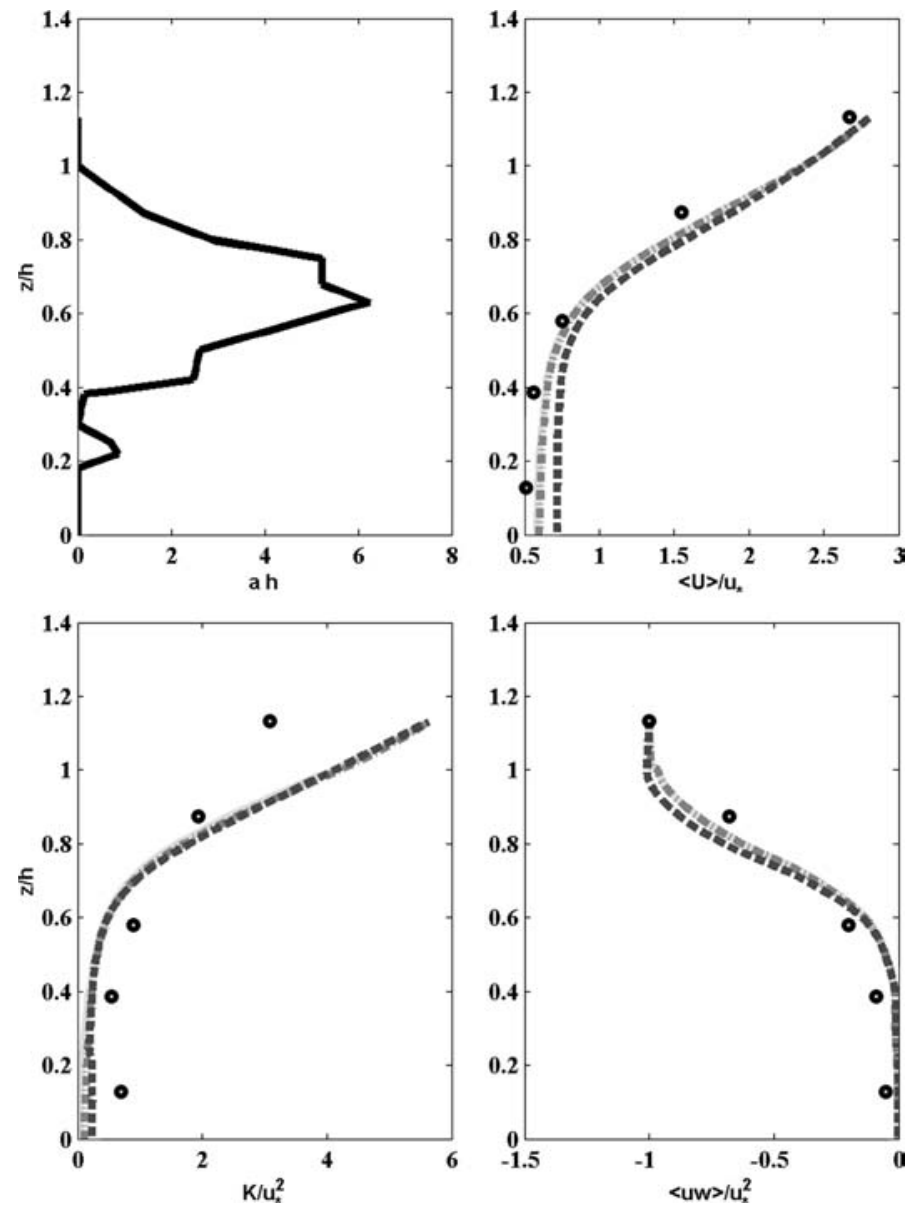

Figure 5. Same as Figure 1 but for the Jack pine canopy (JPI).

elsewhere (Kelliher et al., 1998, 1999; Schulze et al., 1999). The anemometers were mounted on a $26 \mathrm{~m}$ mast surrounded by a uniform aged canopy for distances exceeding $600 \mathrm{~m}$ in all directions. Average tree height was about $20 \mathrm{~m}$, canopy depth was about $8 \mathrm{~m}$, the one-sided, projected leaf area index (LAI) was $2.6 \mathrm{~m}^{2} \mathrm{~m}^{-2}$, and stand density was 1088 trees ha ${ }^{-1}$. There were few under-story shrubs and the ground surface was covered by lichens. The velocity statistics were measured using five sonic anemometers (Solent R3, Gill Instruments, Lymington, U.K.) placed at 25.7, 19.8, 16.2, 12.3, $1.4 \mathrm{~m}$ above the ground (see Figure 6).

\subsection{THE LOBLOLLY PINE CANOPY}

Much of the experimental set-up is described elsewhere (Katul and Albertson, 1998; Katul and Chang, 1999; Siqueira and Katul, 2002). For com- 

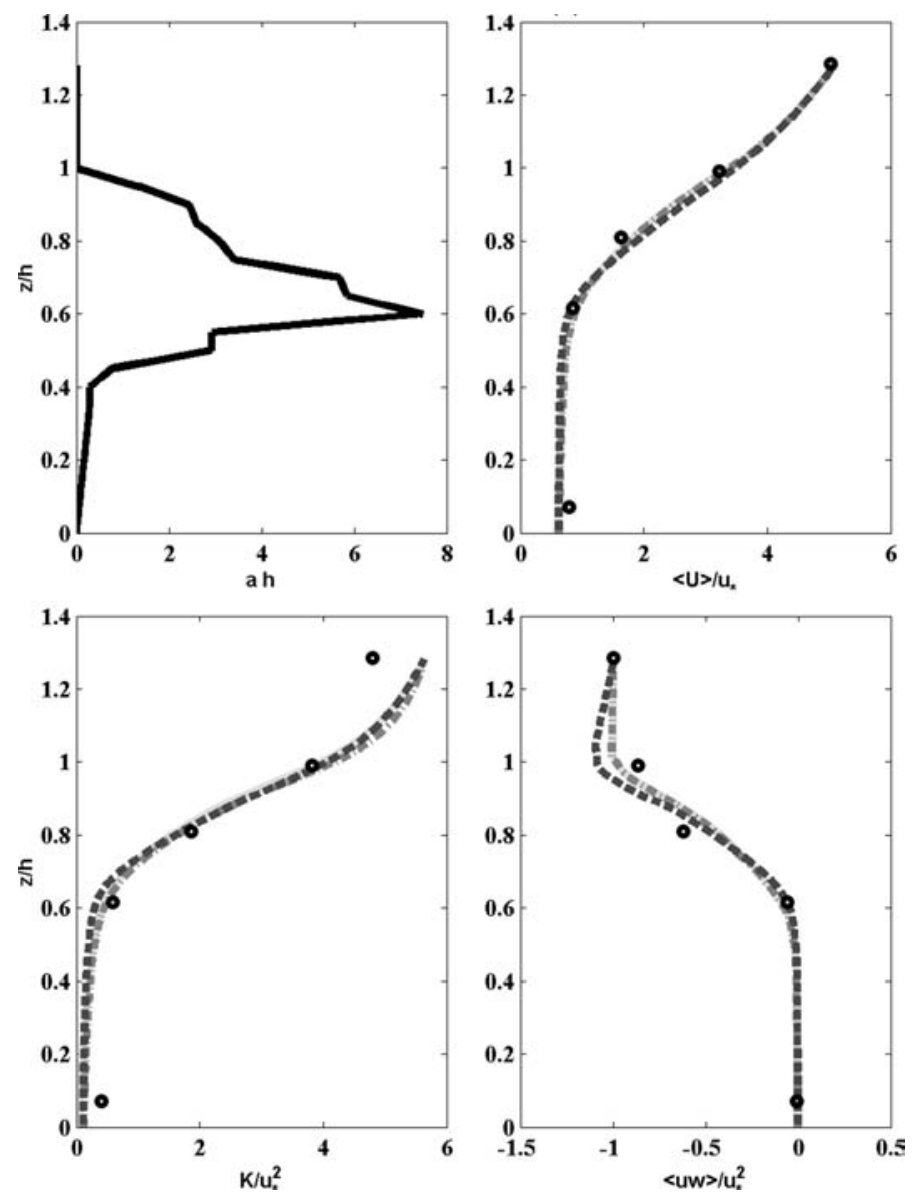

Figure 6. Same as Figure 1 but for the Scots pine canopy (SPI).

pleteness, we review the main features of the site and set-up. The site is at the Blackwood division of the Duke Forest near Durham, North Carolina, U.S.A. The stand is an even-aged southern loblolly pine with a mean canopy height of about $14 \mathrm{~m}( \pm 0.5 \mathrm{~m})$. The three velocity components and virtual potential temperature were simultaneously measured at six levels using five Campbell Scientific CSAT3 (Campbell Scientific, Logan Utah, U.S.A.) triaxial sonic anemometers and a Solent Gill sonic anemometer. The CSAT3 anemometers were positioned at $z / h=0.29,0.425,0.69,0.94$ and 1.14 above the ground surface; the Solent Gill anemometer was mounted at $z / h=1.47$. The shoot silhouette area index, a value analogous to the LAI, was measured in the vertical at about $1 \mathrm{~m}$ intervals by a pair of LICOR LAI 2000 plant canopy analyzers prior to the experiment. The measured $a$ (normalized by canopy height) is shown in Figure 7. The resulting LAI is $3.8 \mathrm{~m}^{2} \mathrm{~m}^{-2}$. 

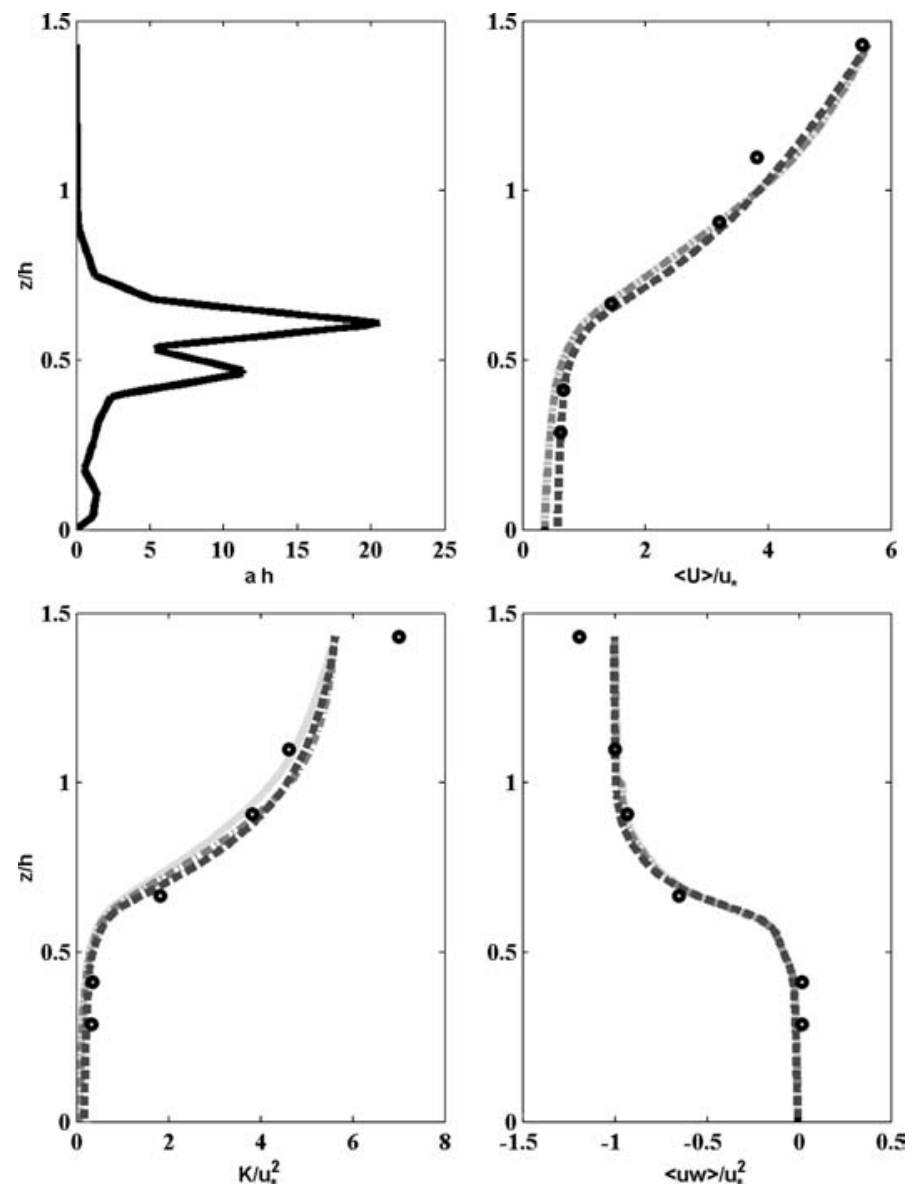

Figure 7. Same as Figure 1 but for the Loblolly pine canopy (LPI).

\subsection{THE BOREAL FOREST CANOPIES}

The data and experimental set-up are described elsewhere (Amiro, 1990), and are briefly reviewed below. The study sites are located near Whiteshell Nuclear Research Establishment in south-eastern Manitoba, Canada. Three sites, comprising of different stands (spruce, Jack pine, and aspen), and located within $15 \mathrm{~km}$ of each other, were used. Individuals within the black spruce forest range in age from 70 to 140 years; the tree density is approximately 7450 trees ha $^{-1}$, and the forest floor is mostly composed of sphagnum moss and low shrubs. The measured leaf area index, obtained using destructive harvesting, is $10.0 \mathrm{~m}^{2} \mathrm{~m}^{-2}$, and the mean canopy height is about $12 \mathrm{~m}$. The pine canopy is mainly composed of a 60 -year old jack pine stand with a tree density of 675 trees ha $^{-1}$. The average tree height is about $15 \mathrm{~m}$ and the leaf area index, also obtained by destructive harvest, is about 

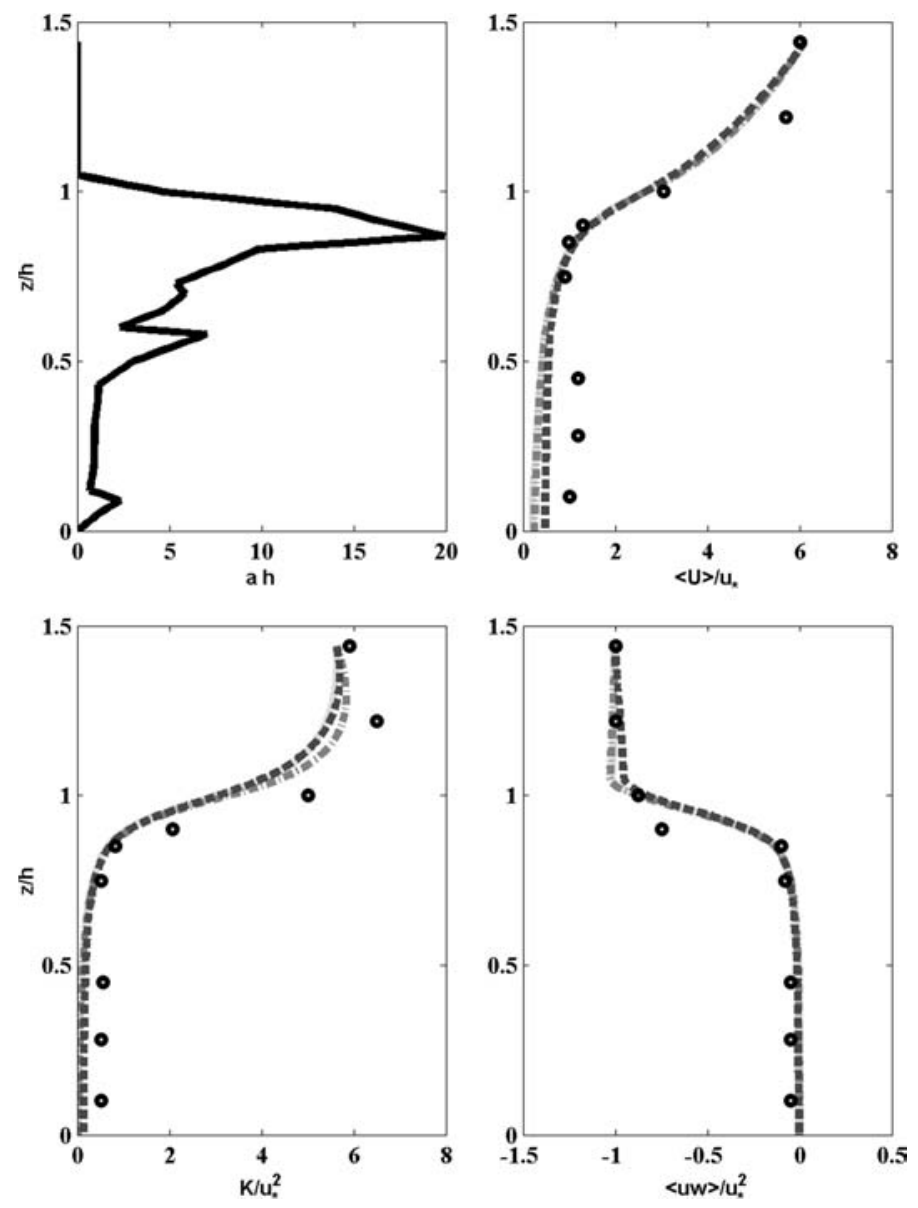

Figure 8. Same as Figure 1 but for the hardwood canopy (HW).

$2.0 \mathrm{~m}^{2} \mathrm{~m}^{-2}$. The aspen canopy is primarily composed of trembling aspen and willow, whose mean tree height and leaf area are about $10 \mathrm{~m}$, and $4.0 \mathrm{~m}^{2} \mathrm{~m}^{-2}$, respectively. The velocity data were acquired by two triaxial sonic anemometers (Applied Technology Inc, Boulder, CO, U.S.A.) each having a $0.15 \mathrm{~m}$ path length. The measurements were obtained by positioning one sonic anemometer above the canopy, and the other roving at different heights. For the spruce site, the anemometer heights were 12.1, 9.2, 6.2, 4.2, and $1.8 \mathrm{~m}$; for the pine sites, the heights were 17, 13.1, 8.7, 5.8, and $1.9 \mathrm{~m}$. For the aspen site, a composite profile was constructed from two towers - with the following heights: $13.1,8.7,5.8,3.4$, and $1.4 \mathrm{~m}$. The leaf area densities for the spruce (Figure 3), aspen (Figure 4), and Jack pine (Figure 5) were digitized by us. 

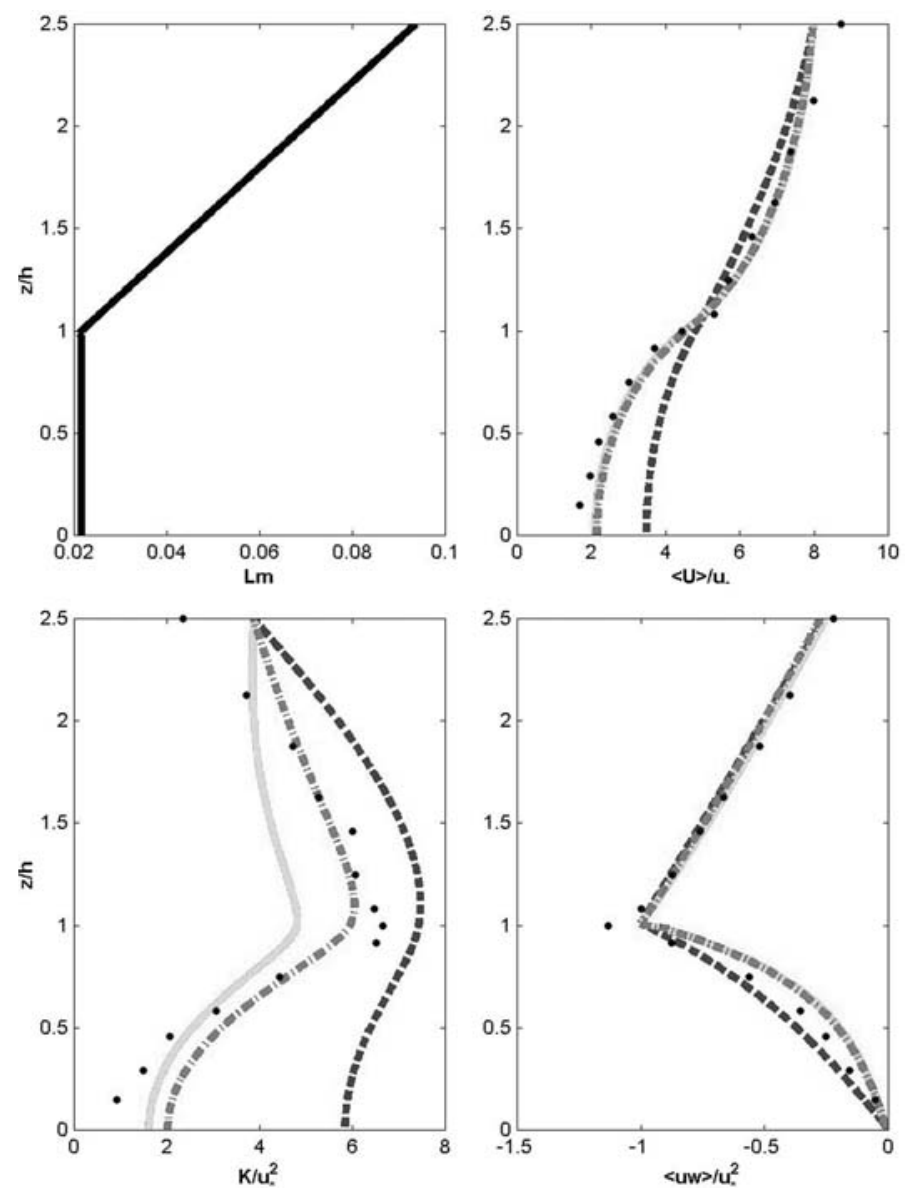

Figure 9. Same as Figure 1 but for the flume experiments. Rather than show the leaf area density (which is constant) in the left panel, we display the normalized mixing length.

\subsection{THE OAK-HICKORY-PINE CANOPY}

The experimental set-up and datasets are described in several studies (Baldocchi and Meyers, 1988; Baldocchi, 1989; Meyers and Baldocchi, 1991). The site is an undisturbed oak-hickory-pine forest, $23 \mathrm{~m}$ in height, near Oak Ridge, Tennessee, U.S.A. The topography at the site is not flat (see e.g., Lee et al., 1994). The velocity measurements, collected at the time when the canopy was fully leafed $\left(\mathrm{LAI}=5.0 \mathrm{~m}^{2} \mathrm{~m}^{-2}\right)$ were conducted at seven levels $(z / h=0.11,0.3,0.43,0.78,0.90,0.95$, and 1.04) using three simultaneous Gill sonic anemometers. These measurements were ensemble averaged based on stability conditions above the canopy as described in Meyers and Baldocchi (1991). The measured $a$ (normalized by canopy height) was digitized by us and is shown in Figure 8. 


\subsection{THE FLUME EXPERIMENTS}

These experiments were conducted at the hydraulics Laboratory, DITIC Politecnico di Torino, in a rectangular channel $18 \mathrm{~m}$ long, $0.90 \mathrm{~m}$ wide and $1 \mathrm{~m}$ deep. The walls are constructed of glass to allow the passage of laser light. The model canopy is an array of vertical stainless steel cylinders, $0.12 \mathrm{~m}$ high, and $4 \mathrm{~mm}$ in diameter equally spaced along the $9 \mathrm{~m}$ long and $0.9 \mathrm{~m}$ wide test section. The canopy roughness density was set at $1072 \operatorname{rods~m}^{-2}$, which is equivalent to an element area index (front area per unit volume) of $4.27 \mathrm{~m}^{2} \mathrm{~m}^{-3}$. A two-component laser Doppler anemometer (LDA) sampled the velocity time series at $2500-3000 \mathrm{~Hz}$. The LDA is non-intrusive and has a small averaging volume thereby permitting velocity excursion measurements close to the rods. Further details about the LDA configuration and signal processing can be found elsewhere (Poggi et al., 2004a). Velocity measurements were conducted at 11 horizontal positions, and at each horizontal position, 15 profile measurements were collected thereby permitting us to construct real space-time averages. The uniform flow water depth was $0.60 \mathrm{~m}$.

\section{Results and Discussion}

Figures 1 to 9 show the comparison between the measured and modelled $U$, $K$, and $\overline{u^{\prime} w^{\prime}}$ for all the CSL experiments, and Table III shows the quantitative comparison between measured and modelled flow variables. For the $K-\varepsilon$ models, we present the results for both eddy viscosity formulations (i.e., Equation(4a)). By and large, both $K-\varepsilon$ models and the $K-U$ approach agree well with the measurements except for the three Boreal forests datasets of Amiro (1990), as evidenced in Table III and Figures 4, 5 and 6. There are three generic features in all these datasets (i.e., Figures 2 to 8 ) that the models did not reproduce well:

(1) the height-dependent $\overline{u^{\prime} w^{\prime}}$ with $z$ for $z / h>1$ (Figures 3, 4, 6, and 7),

(2) the boundary conditions on $K$ in Figures 4, 5, and 6 (i.e., the three Boreal stands), and,

(3) the mild secondary maximum in $U$ in Figure 8.

Regarding the height-dependency of $\overline{u^{\prime} w^{\prime}}$ with $z$ for $z / h>1$, there are several plausible explanations ranging from topographic variability, statistically inhomogeneous variability in canopy morphology leading to an inhomogeneous momentum sink, and significant atmospheric stability effects on momentum transport. If topographic variations induce a sufficiently large $\partial \bar{P} / \partial x$ ( $P$ being pressure), then correcting for a height-dependent $\overline{u^{\prime} w^{\prime}}$ with $z$ for $z / h>1$ can be achieved using a revised mean momentum budget equation to include $\partial \bar{P} / \partial x$ (Lee et al., 1994) as is done for our flume experiment. 
TABLE III

Comparisons between the three models and measurements at all field sites and all heights (see Table II for vegetation labels).

\begin{tabular}{|c|c|c|c|c|c|c|c|c|c|}
\hline \multirow[b]{2}{*}{ Model } & \multirow[b]{2}{*}{ Variable } & \multicolumn{8}{|c|}{ Canopy type } \\
\hline & & RI & $\mathrm{CO}$ & SP & AS & JPI & SPI & LPI & HW \\
\hline \multicolumn{10}{|c|}{ Mean velocity comparisons } \\
\hline \multirow[t]{6}{*}{$K-\varepsilon^{\mathrm{a}}$} & $n$ & 10 & 19 & 5 & 8 & 5 & 5 & 6 & 9 \\
\hline & $m$ & 0.99 & 1.04 & 0.71 & 0.90 & 0.71 & 0.97 & 0.91 & 0.94 \\
\hline & $b$ & 0.12 & -0.07 & -0.11 & -0.12 & 0.09 & 0.05 & 0.19 & 0.50 \\
\hline & $r$ & 0.99 & 1.00 & 1.00 & 0.99 & 1.00 & 1.00 & 0.99 & 0.98 \\
\hline & RMSE & 0.32 & 0.13 & 0.74 & 0.36 & 0.50 & 0.12 & 0.27 & 0.58 \\
\hline & Bias & -0.10 & 0.01 & 0.57 & 0.30 & 0.37 & 0.02 & 0.06 & -0.39 \\
\hline \multirow[t]{5}{*}{$K-U$} & $m$ & 1.00 & 1.04 & 0.71 & 0.90 & 0.71 & 0.97 & 0.91 & 0.95 \\
\hline & $b$ & 0.08 & -0.10 & -0.12 & -0.13 & 0.08 & 0.02 & 0.17 & 0.47 \\
\hline & $r$ & 0.99 & 1.00 & 1.00 & 0.99 & 1.00 & 1.00 & 0.99 & 0.98 \\
\hline & RMSE & 0.31 & 0.13 & 0.74 & 0.37 & 0.51 & 0.13 & 0.26 & 0.56 \\
\hline & Bias & -0.07 & 0.04 & 0.58 & 0.31 & 0.38 & 0.04 & 0.06 & -0.37 \\
\hline \multirow[t]{5}{*}{$K-\varepsilon^{\mathrm{b}}$} & $m$ & 1.13 & 1.09 & 0.78 & 1.17 & 0.98 & 1.16 & 0.95 & 0.99 \\
\hline & $b$ & -0.36 & -0.41 & -0.28 & -0.93 & -0.65 & -0.53 & -0.03 & 0.34 \\
\hline & $r$ & 0.99 & 1.00 & 0.99 & 0.99 & 1.00 & 1.00 & 1.00 & 0.98 \\
\hline & RMSE & 0.42 & 0.33 & 0.74 & 0.62 & 0.68 & 0.30 & 0.22 & 0.50 \\
\hline & Bias & 0.10 & 0.26 & 0.66 & 0.57 & 0.68 & 0.13 & 0.15 & -0.31 \\
\hline \multicolumn{10}{|c|}{ Reynolds stress comparisons } \\
\hline \multirow[t]{5}{*}{$K-\varepsilon^{\mathrm{a}}$} & $m$ & 0.66 & 1.17 & 0.85 & 1.09 & 0.94 & 0.97 & 1.11 & 0.94 \\
\hline & $b$ & -0.08 & -0.06 & -0.05 & 0.01 & -0.07 & -0.04 & 0.03 & -0.09 \\
\hline & $r$ & 0.72 & 0.96 & 0.98 & 0.97 & 0.99 & 0.98 & 0.99 & 0.94 \\
\hline & RMSE & 0.26 & 0.17 & 0.12 & 0.10 & 0.07 & 0.09 & 0.09 & 0.16 \\
\hline & Bias & -0.02 & 0.11 & -0.02 & 0.03 & 0.05 & 0.03 & 0.04 & 0.07 \\
\hline \multirow[t]{5}{*}{$K-U$} & $m$ & 0.65 & 1.15 & 0.85 & 1.10 & 0.92 & 0.95 & 1.11 & 0.94 \\
\hline & $b$ & -0.07 & -0.06 & -0.04 & 0.01 & -0.07 & -0.04 & 0.03 & -0.09 \\
\hline & $r$ & 0.72 & 0.96 & 0.98 & 0.97 & 0.99 & 0.98 & 0.99 & 0.94 \\
\hline & RMSE & 0.27 & 0.16 & 0.12 & 0.10 & 0.07 & 0.09 & 0.09 & 0.16 \\
\hline & Bias & -0.03 & 0.10 & -0.02 & 0.03 & 0.04 & 0.01 & 0.03 & 0.06 \\
\hline \multirow[t]{5}{*}{$K-\varepsilon^{\mathrm{b}}$} & $m$ & 0.79 & 1.17 & 0.87 & 1.12 & 0.88 & 1.01 & 1.10 & 0.97 \\
\hline & $b$ & 0.01 & 0.00 & -0.04 & 0.12 & -0.05 & 0.00 & 0.03 & -0.09 \\
\hline & $r$ & 0.79 & 0.98 & 0.98 & 0.97 & 0.99 & 0.99 & 0.99 & 0.94 \\
\hline & RMSE & 0.23 & 0.11 & 0.10 & 0.13 & 0.08 & 0.07 & 0.09 & 0.16 \\
\hline & Bias & -0.09 & 0.06 & -0.01 & -0.07 & 0.00 & 0.00 & 0.03 & 0.08 \\
\hline
\end{tabular}


Table III. (Continued)

\begin{tabular}{|c|c|c|c|c|c|c|c|c|c|}
\hline \multirow[b]{2}{*}{ Model } & \multirow[b]{2}{*}{ Variable } & \multicolumn{8}{|c|}{ Canopy type } \\
\hline & & RI & $\mathrm{CO}$ & SP & AS & JPI & SPI & LPI & HW \\
\hline \multicolumn{10}{|c|}{ Turbulent kinetic energy comparisons } \\
\hline \multirow[t]{5}{*}{$K-\varepsilon^{\mathrm{a}}$} & $m$ & 0.86 & 1.15 & 0.73 & 0.92 & 0.68 & 0.91 & 1.08 & 1.08 \\
\hline & $b$ & 0.97 & 0.58 & 0.30 & 0.45 & 0.55 & 0.36 & 0.22 & 0.52 \\
\hline & $r$ & 0.86 & 0.98 & 0.99 & 0.99 & 1.00 & 1.00 & 0.98 & 0.98 \\
\hline & RMSE & 1.21 & 0.85 & 0.55 & 0.40 & 0.47 & 0.29 & 0.65 & 0.87 \\
\hline & Bias & -0.79 & -0.74 & 0.12 & -0.33 & -0.14 & -0.16 & -0.43 & -0.68 \\
\hline \multirow[t]{5}{*}{$K-U$} & $m$ & 0.72 & 1.09 & 0.68 & 0.88 & 0.63 & 0.80 & 1.03 & 1.06 \\
\hline & $b$ & 0.97 & 0.51 & 0.27 & 0.44 & 0.56 & 0.36 & 0.19 & 0.48 \\
\hline & $r$ & 0.85 & 0.98 & 0.99 & 0.99 & 1.00 & 1.00 & 0.97 & 0.98 \\
\hline & RMSE & 1.21 & 0.71 & 0.75 & 0.37 & 0.58 & 0.47 & 0.65 & 0.75 \\
\hline & Bias & -0.56 & -0.62 & 0.29 & -0.24 & -0.04 & 0.12 & -0.29 & -0.59 \\
\hline \multirow[t]{5}{*}{$K-\varepsilon^{\mathrm{b}}$} & $m$ & 0.81 & 1.15 & 0.71 & 1.00 & 0.72 & 0.90 & 1.06 & 1.09 \\
\hline & $b$ & 0.66 & 0.20 & 0.21 & -0.07 & 0.21 & 0.06 & 0.06 & 0.44 \\
\hline & $r$ & 0.90 & 1.00 & 0.99 & 0.99 & 1.00 & 1.00 & 0.97 & 0.98 \\
\hline & RMSE & 0.91 & 0.48 & 0.67 & 0.20 & 0.47 & 0.30 & 0.61 & 0.83 \\
\hline & Bias & -0.34 & -0.41 & 0.30 & 0.08 & 0.27 & 0.18 & -0.23 & -0.62 \\
\hline
\end{tabular}

The regression analysis used to evaluate the models is $\hat{y}=m \hat{x}+b$, where $\hat{y}$ is the normalized measured variable and $\hat{x}$ is the normalized modelled variable (i.e., $U / u_{*}, \overline{u^{\prime} w^{\prime}} / u_{*}^{2}$, and $K / u_{*}^{2}$ ). The friction velocity $\left(u_{*}\right)$ at the canopy top is used as the normalizing velocity for all sites. The slope $(m)$, the intercept $(b)$, the correlation coefficient $(r)$, the RMSE, and the mean bias (computed from $\hat{x}-\hat{y}$ ) are presented for all three variables and all threemodels. The data size $n$ for each site used in the comparison is also shown. For LPI, the published RMSE values by Katul and Albertson (1998) for $U, \overline{u^{\prime} w^{\prime}}$, and $K$ are $0.11,0.02$, and 0.09 for the second-order closure model, and $0.13,0.02$, and 0.09 for the third-order closure model. For RI, the published RMSE values by Katul et al. (2001b) for $U$ and $\overline{u^{\prime} w^{\prime}}$ are 0.05 and 0.2 for the secondorder closure model.

${ }^{\mathrm{a}}$ Model calculations are with $v_{t}=C_{\mu}^{1 / 4} l_{\mathrm{m}} K^{1 / 2}$; ${ }^{\mathrm{b}}$ model calculations are with $v_{t}=C_{\mu} K^{2} / \varepsilon$.

The addition of $\partial \bar{P} / \partial x$, which violates planar homogeneity, may necessitate, in some cases, the addition of the remaining two mean momentum advective flux terms in which case the model is no longer one-dimensional. Given the study objectives, noting that detailed topographic information is unpublished for these sites, and noting the variable wind direction for each run, the simplest approximation was to set $\partial \bar{P} / \partial x=0$. For the flume experiment, $\partial \bar{P} / \partial x$ is set a priori and was considered in the calculations of the mean momentum equation.

According to Amiro (1990), the three Boreal forests are on flat terrain so a significant $\partial \bar{P} / \partial x$ is not likely at those sites. This means that either atmospheric stability effects are significant (which is likely for the three Boreal 
forests) or statistical inhomogeneity in the momentum sink is present to induce a gradient in $\overline{w^{\prime} u^{\prime}}$ not captured by the three models.

Regarding the upper boundary conditions on $K / u_{*}^{2}$ for the three Boreal stands, it is likely that the measurement sample size used to generate the ensemble statistics is very small ( $<5$ neutral runs). In contrast, the Duke Forest experiments, for example, included in excess of 100 runs, simultaneously collected at six levels, and filtered for neutral flows within and above the canopy. So, the bias and large root-mean squared error (RMSE) may be attributed to the small sample size in constructing the ensemble measured statistics.

The weak secondary maximum in Figure 8 may be attributed to a finite $\partial \bar{P} / \partial x$ at the hardwood forest, a site known to be surrounded by complex topography (Lee et al., 1994). Third-order closure model calculations by Meyers and Baldocchi (1991), in which the turbulent flux divergence was explicitly considered, did not reproduce the secondary maximum, contrary to second-order closure model results in Wilson and Shaw (1977). Hence, these model results suggest that flux divergence alone cannot explain the onset of this secondary maximum, and it is likely that a finite $\partial \bar{P} / \partial x$ must be added in the model for this site.

In Figure 10, we show the overall comparison between measured and modelled flow statistics for all field sites. It is clear that the three models reproduce the overall measured $U, K$, and $\overline{u^{\prime} w^{\prime}}$ for a wide range of leaf area and canopy heights. The observed bias in modelled $K / u_{*}^{2}$ (Figure 10) is attributed to the three Boreal forests (see Table III). Table IV reports regression statistics for this overall comparison and for each model.

The published normalized RMSE for second- and third-order closure model calculations for the Loblolly pine stand and the rice canopy (Katul and Albertson, 1998; Katul et al., 2001b) are comparable to values reported in Table III. That is, the predictive skills of $K-U$ and $K-\varepsilon$ models are no worse than second- and third-order closure models, at least for these two sites.

We also confirmed that the RMSE variation for the three flow variables does not vary with $h$, LAI, and mean leaf area density $(=\mathrm{LAI} / h)$ (figures not shown). Finally, Figure 10 and Table IV demonstrate that the $K-\varepsilon$ calculations conducted using $v_{t}=v_{t}^{(i i)}=C_{\mu} \frac{K^{2}}{\varepsilon}$ are comparable to those conducted using $v_{t}=v_{t}^{(i)}$. That is, specifying a constant mixing length scale within the canopy without the $\varepsilon$ budget is no worse than estimating such a length scale via the standard $K-\varepsilon$ modelling (i.e., $l_{\mathrm{m}}=C_{\mu} \frac{K^{3 / 2}}{\varepsilon}$ ).

However, for the flume experiments, the standard $K-\varepsilon$ model with $v_{t}=v_{t}^{(i i)}=C_{\mu} \frac{K^{2}}{\varepsilon}$ was clearly inferior to $K-U$ and $K-\varepsilon$ model calculations conducted with $v_{t}=v_{t}^{(i)}$. A logical question then is whether this poor performance of the standard $K-\varepsilon$ model is connected with the poor estimates of the dissipation. Hence, measured and modelled estimates of the mean dissi- 



Figure 10. Comparison between measured and modelled $U / u_{*}, \overline{u^{\prime} w^{\prime}} / u_{*}^{2}$, and $K / u_{*}^{2}$ for all field sites and heights. The open circles and open squares are for $K-\varepsilon$ model calculations using $v_{t}=C_{\mu} K^{1 / 2} l_{\mathrm{m}}$ and $v_{t}=C_{\mu} \frac{K^{2}}{\varepsilon}$, respectively, and the plusses are for the $K-U$ model calculations. The 1:1 line is also shown. 
TABLE IV

Overall comparisons between the three models and measurements at all field sites and all heights.

\begin{tabular}{llrrr}
\hline Variable & Statistic & $K-\varepsilon^{\mathrm{a}}$ & $K-U$ & $K-\varepsilon^{\mathrm{b}}$ \\
\hline$U$ & $m$ & 0.97 & 0.97 & 1.14 \\
& $b$ & 0.04 & 0.02 & -0.56 \\
& $r$ & 0.98 & 0.98 & 0.97 \\
& RMSE & 0.35 & 0.35 & 0.53 \\
$K$ & $m$ & 0.94 & 0.88 & 1.01 \\
& $b$ & 0.45 & 0.44 & -0.19 \\
& & 0.95 & 0.94 & 0.95 \\
& & 0.69 & 0.70 & 0.60 \\
$u^{\prime} w^{\prime}$ & RMSE & 0.97 & 0.96 & 1.07 \\
& $m$ & -0.06 & -0.05 & 0.09 \\
& $b$ & 0.93 & 0.93 & 0.94 \\
& $r$ & 0.16 & 0.15 & 0.15 \\
\hline
\end{tabular}

The regression analysis used to evaluate the models is $\hat{y}=m \hat{x}+b$, where $\hat{y}$ is the normalized measured variable and $\hat{x}$ is the normalized modelled variable. The slope $(m)$, intercept $(b)$, correlation coefficient $(r)$, and RMSE are presented for all three variables.

${ }^{a}$ Model calculations are with $v_{t}=C_{\mu}^{1 / 4} l_{\mathrm{m}} K^{1 / 2} ;{ }^{\mathrm{b}}$ model calculations are with $v_{t}=C_{\mu} K^{2} / \varepsilon$.

pation rate for the flume experiment were compared. Given the high frequency sampling (i.e., $2500-3000 \mathrm{~Hz}$ ), it is possible to estimate horizontally averaged $\varepsilon$ profiles within the canopy using locally isotropic assumptions. The so-called 'measured' dissipation rate was computed using (Tennekes and Lumley, 1972):

$$
\varepsilon=15 v \overline{\left(\frac{\partial u}{\partial x}\right)^{2}}
$$

where $v$ is the molecular kinematic viscosity, and the horizontal velocity gradient is estimated from longitudinal velocity time series using Taylor's frozen turbulence hypothesis. Dissipation estimates were then ensembleaveraged in the planes parallel to the flume base using the area-weighted procedure discussed in Poggi et al. (2004a). While this estimate of the dissipation is spatially averaged, it must be treated with caution because of likely violations of Taylor's hypothesis within the canopy volume. Despite such a limitation, Equation (11) provides an independent estimate of $\varepsilon$ from single point statistics without requiring a TKE budget equation. Stated differently, Equation (11) is independent of simplifications or assumptions already made in the derivation of the $K-\varepsilon$ model. Figure 11 compares the computed and socalled 'measured' mean dissipation rates using the two $K-\varepsilon$ models and the 


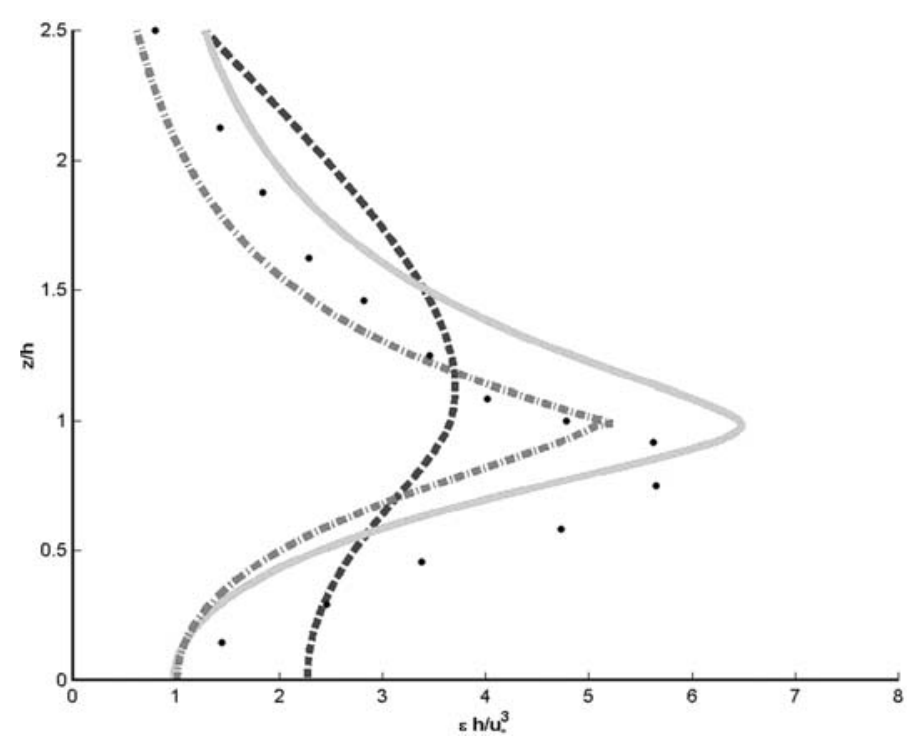

Figure 11. Same as Figure 1 but for the spatially and temporally averaged turbulent kinetic energy dissipation rate of the flume experiment.

$K-U$ model. Clearly, none of the models reproduce well the 'measured' $\varepsilon$ within the canopy though the standard $K-\varepsilon$ is much worse than the other two models. In short, the poor performance reported for the standard $K-\varepsilon$ in Figure 9 is linked with its poor dissipation estimate as evidenced by Figure 11 .

\section{Conclusion}

It was suggested that $K-\varepsilon$ models introduce numerous closure constants over one-equation models thereby 'making it difficult to differentiate profoundness of the set of closure assumptions from the mere flexibility due to those coefficients' (Wilson et al., 1998). Here, we showed that the degrees of freedom in these coefficients can be reduced to levels comparable to one-equation models (Sanz, 2003). With these requirements on the closure constants, standard $K-\varepsilon$ model predictions appear comparable to second-order (and higher order) closure models. For the one-dimensional case, the $K-\varepsilon$ model performance was no better than one-equation models however. The proposed one-equation model (referred to as the $K-U$ model) was computationally three to four times faster than the standard $K-\varepsilon$ model. This makes oneequation models attractive for linking the biosphere to the atmosphere in large-scale atmospheric models or multi-layer soil-vegetation-atmosphere transfer schemes within heterogeneous landscapes. We also showed that the 
additional $\varepsilon$ budget, with its numerous assumptions, did not add critical or sensitive information to $K-\varepsilon$ calculations of $K, U$, and $\overline{u^{\prime} w^{\prime}}$ profiles. Perhaps this finding is not too surprising when specifying a 'canonical' length scale for canopy turbulence. The key variable, $v_{t}$, is proportional to $K^{1 / 2}$ (rather than $K^{2}$ as is the case in standard $K-\varepsilon$ models) thereby making it less sensitive to errors in modelled $K$.

The broader implication is that canopy turbulence, having a well-defined mixing length, appears very amenable to simplified mathematical models that mimic faithfully the behaviour of turbulence yet are computationally efficient to be integrated in more complex atmospheric, hydrologic, or ecological models. To cite Lumley (1992), in our present state of understanding, these simple models will always be based in part on good physics, in part, on bad physics, and in part, on shameless phenomenology. Demonstrating how sensitive the computed flow statistics are to bad physics and shameless phenomenology is necessary (but not sufficient) towards building robust and accurate new formulation for canopy turbulence.

\section{Acknowledgements}

The first author acknowledges support from the Center on Global Change (Duke University) during his fall of 2002 leave. Additional support was provided by the National Science Foundation (NSF-EAR and NSF-DMS), the Biological and Environmental Research (BER) Program, U.S. Department of Energy, through the Southeast Regional Center (SERC) of the National Institute for Global Environmental Change (NIGEC), and through the Terrestrial Carbon Processes Program (TCP) and the FACE project. The second author was supported by the Terrestrial Ecology Program, NASA (Grant NAG5-11231). The datasets and the source code (in MATLAB) for all three models are available upon request.

\section{References}

Albertson, J. D., Katul, G. G., and Wiberg, P.: 2001, 'Relative Importance of Local and Regional Controls on Coupled Water, Carbon, and Energy Fluxes', Adv. Water Resour. 24, 1103-1118.

Amiro, B. D.: 1990, 'Comparison of Turbulence Statistics within 3 Boreal Forest Canopies', Boundary-Layer Meteorol. 51, 99-121.

Ayotte, K. W., Finnigan, J. J., and Raupach, M. R.: 1999, 'A Second-Order Closure for Neutrally Stratified Vegetative Canopy Flows', Boundary-Layer Meteorol. 90, 189216.

Baldocchi, D. D.: 1989, 'Turbulent Transfer in a Deciduous Forest', Tree Phys. 5, 357-377.

Baldocchi, D. D. and Meyers, T. D.: 1988, 'A Spectral and Lag-Correlation Analysis of Turbulence in a Deciduous Forest Canopy', Boundary-Layer Meteorol. 45, 31-58. 
Bradshaw, P., Launder, B. E., and Lumley, J. L.: 1991, 'Collaborative Testing of Turbulence Models', J. Fluids Engr.-Trans. ASME 113, 3-4.

Brutsaert, W.: 1982, Evaporation into the Atmosphere: Theory, History, and Applications, Kluwer Academic Publishers, Boston, 299 pp.

Castro F. A., Palma, J. M., and Lopes, A. S.: 2003, 'Simulation of the Askervein Flow. Part 1: Reynolds Averaged Navier-Stokes Equations (K-Epsilon Turbulence Model)', BoundaryLayer Meteorol. 107, 501-530.

Finnigan, J. J.: 2000, 'Turbulence in Plant Canopies', Annu. Rev. Fluid Mech. 32, 519-571.

Garratt, J. R.: 1992, The Atmospheric Boundary Layer, Cambridge University Press, Cambridge, U.K., 316 pp.

Green, S.: 1992, 'Modelling Turbulent Air Flow in a Stand of Widely Spaced Trees', J. Comp. Fluid Dyn. Appl. 5, 294-312.

Horn, H. S., Nathan, R., and Kaplan, S. R.: 2001, 'Long-Distance Dispersal of Tree Seeds by Wind', Ecol. Res. 16, 877-885.

Kaimal, J. C. and Finnigan, J. J.: 1994, Atmospheric Boundary Layer Flows: Their Structure and Measurement, Oxford University Press, New York, 289 pp.

Katul, G. G. and Albertson, J. D.: 1998, 'An Investigation of Higher-Order Closure Models for a Forested Canopy', Boundary-Layer Meteorol. 89, 47-74.

Katul, G. G. and Albertson, J. D.: 1999, 'Modeling $\mathrm{CO}_{2}$ Sources, Sinks, and Fluxes within a Forest Canopy', J. Geophys. Res. (Atmospheres) 104, 6081-6091.

Katul, G. G. and Chang, W. H.: 1999, 'Principal Length Scales in Second-Order Closure Models for Canopy Turbulence', J. Appl. Meteorol. 38, 1631-1643.

Katul, G. G., Geron, C. D., Hsieh, C. I., Vidakovic, B., and Guenther, A. B.: 1998, 'Active Turbulence and Scalar Transport near the Forest-Atmosphere Interface', J. Appl. Meteorol. 37, 1533-1546.

Katul, G. G., Lai, C. T., Schafer, K., Vidakovic, B., Albertson, J. D., Ellsworth, D., and Oren, R.: 2001a, 'Multiscale Analysis of Vegetation Surface Fluxes: from Seconds to Years', $A d v$. Water Resour. 24, 1119-1132.

Katul, G. G., Leuning, R., Kim, J., Denmead, O. T., Miyata, A., and Harazono, Y.: 2001b, 'Estimating $\mathrm{CO}_{2}$ Source/Sink Distributions within a Rice Canopy Using Higher-Order Closure Model', Boundary-Layer Meteorol. 98, 103-125.

Kelliher, F. M., Lloyd, J., Arneth, A., Byers, J. N., McSeveny, T., Milukova, I., Grigoriev, S., Panfyorov, M., Sogatchev, A., Varlargin, A., Ziegler, W., Bauer, G., and Schulze, E. D.: 1998, 'Evaporation from a Central Siberian Pine Forest', J. Hydrol. 205, 279-296.

Kelliher, F. M., Lloyd, J., Arneth, A., Luhker, B., Byers, J. N., McSeveny, T. M., Milukova, I., Grigoriev, S., Panfyorov, M., Sogatchev, A., Varlargin, A., Ziegler, W., Bauer, G., Wong, S. C., and Schulze, E. D.: 1999, 'Carbon Dioxide Efflux Density from the Floor of a Central Siberian Pine Forest', Agric. For. Meteorol. 94, 217-232.

Kobayashi, M. H., Pereira, J., and Siqueira, M.: 1994, 'Numerical Study of the Turbulent Flow over and in a Model Forest on a 2D Hill', J. Wind Eng. Ind. Aerodyn. 53, 357-374.

Lai, C. T., Katul, G. G., Butnor, J., Siqueira, M., Ellsworth, D., Maier, C., Johnsen, K., McKeand, S., and Oren, R.: 2002, 'Modelling the Limits on the Response of Net Carbon Exchange to Fertilization in a South-Eastern Pine Forest', Plant Cell Environ. 25, 10951119.

Lai, C. T., Katul, G. G., Ellsworth, D., and Oren, R.: 2000a, 'Modelling Vegetation-Atmosphere $\mathrm{CO}_{2}$ Exchange by a Coupled Eulerian-Langrangian Approach', Boundary-Layer Meteorol. 95, 91-122.

Lai, C. T., Katul, G. G., Oren, R., Ellsworth, D., and Schafer, K.: 2000b, 'Modeling $\mathrm{CO}_{2}$ and Water Vapor Turbulent Flux Distributions within a Forest Canopy', J. Geophys. Res. (Atmospheres) 105, 26333-26351. 
Launder, B. and Spalding, D. B.: 1974, 'The Numerical Computation of Turbulent Flows', Comp. Meth. Appl. Mech. Eng. 3, 269-289.

Launder, B. E.: 1996, ‘An Introduction to Single-Point Closure Methodology', in J. Lumley (ed.), Simulation and Modeling of Turbulent Flows, Oxford University Press, New York, pp. 243-311.

Lee, X. H., Shaw, R. H., and Black, T. A.: 1994, 'Modeling the Effect of Mean PressureGradient on the Mean Flow within Forests', Agric. For. Meteorol. 68, 201-212.

Leuning, R., Denmead, O. T., Miyata, A., and Kim, J.: 2000, 'Source/Sink Distributions of Heat, Water Vapour, Carbon Dioxide and Methane in a Rice Canopy Estimated Using Lagrangian Dispersion Analysis', Agric. For. Meteorol. 104, 233-249.

Li, Z. J., Miller, D. R., and Lin, J. D.: 1985, 'A First Order Closure Scheme to Describe Counter-Gradient Momentum Transport in Plant Canopies', Boundary-Layer Meteorol. 33, 77-83.

Liu, J., Black, T. A., and Novak, M. D.: 1996, 'E-Epsilon Modeling of Turbulent Air Flow Downwind of a Model Forest Edge', Boundary-Layer Meteorol. 77, 21-44.

Lumley, J. L.:1992, 'Some Comments on Turbulence', Phys. Fluids A (Fluid Dynamics) 4, 203-211.

Mahrt, L., Lee, X. L., Black, A., Neumann, H., and Staebler, R.: 2000, 'Nocturnal Mixing in a Forest Subcanopy', Agric. For. Meteorol. 101, 67-78.

Massman, W. J.: 1997, 'An Analytical One-Dimensional Model of Momentum Transfer by Vegetation of Arbitrary Structure', Boundary-Layer Meteorol. 83, 407-421.

Massman, W. J. and Weil, J. C.: 1999, 'An Analytical One-Dimensional Second-Order Closure Model of Turbulence Statistics and the Lagrangian Time Scale within and above Plant Canopies of Arbitrary Structure', Boundary-Layer Meteorol. 91, 81-107.

Meyers, T. and Paw U, K. T.: 1986, 'Testing of a Higher-Order Closure-Model for Modeling Air-Flow within and above Plant Canopies', Boundary-Layer Meteorol. 37, 297311.

Meyers, T. P.: 1987, 'The Sensitivity of Modeled $\mathrm{SO}_{2}$ Fluxes and Profiles to Stomatal and Boundary-Layer Resistances', Water Air Soil Poll. 35, 261-278.

Meyers, T. P. and Baldocchi, D. D.: 1991, 'The Budgets of Turbulent Kinetic-Energy and Reynolds Stress within and above a Deciduous Forest', Agric. For. Meteorol. 53, 207-222.

Meyers, T. P. and Paw U, K. T.: 1987, 'Modeling the Plant Canopy Micrometeorology with Higher-Order Closure Principles', Agric. For. Meteorol. 41, 143-163.

Nathan, R., Katul, G. G., Horn, H., Thomas, S., Oren, R., Avissar, R., Pacala, S., and Levin, S.: 2002, 'Mechanisms of Long-Distance Dispersal of Seeds by Wind', Nature 418, 409413.

Parlange, M. B. and Brutsaert, W.: 1989, 'Regional Roughness of the Landes Forest and Surface Shear-Stress under Neutral Conditions', Boundary-Layer Meteorol. 48, 69-81.

Paw U, K. T. and Meyers, T. P.: 1989, 'Investigations with a Higher-Order Canopy Turbulence Model into Mean Source-Sink Levels and Bulk Canopy Resistances', Agric. For. Meteorol. 47, 259-271.

Pinard, J. and Wilson, J. D.: 2001, 'First- and Second-Order Closure Models for Wind in a Plant Canopy', J. Appl. Meteorol. 40, 1762-1768.

Poggi, D., Porporato, A., Ridolfi, L., Albertson, J. D., and Katul, G. G.: 2004a, 'The Effect of Vegetation Density on Canopy Sublayer Turbulence', Boundary-Layer Meteorol. 111, 565587.

Poggi, D., Katul, G. G., and Albertson, J. D.: 2004b, 'A Note on the Contribution of Dispersive Fluxes to Momentum Transfer within Canopies', Boundary-Layer Meteorol. 111, 615-621.

Pope, S. B.: 2000, Turbulent Flows, Cambridge University Press, New York, 771 pp. 
Raupach, M. R.: 1989a, 'Applying Lagrangian Fluid Mechanics to Infer Scalar Source Distributions from Concentration Profiles in Plant Canopies', Agric. For. Meteorol. 47, 85108.

Raupach, M. R.: 1989b, 'A Practical Lagrangian Method for Relating Scalar Concentrations to Source Distributions in Vegetation Canopies', Quart. J. Roy. Meteorol. Soc. 115, 609632.

Raupach, M. R.: 1991, 'Vegetation-Atmosphere Interaction in Homogeneous and Heterogeneous Terrain - Some Implications of Mixed-Layer Dynamics', Vegetatio 91, 105-120.

Raupach, M. R.: 1994, 'Simplified Expressions for Vegetation Roughness Length and ZeroPlane Displacement as Functions of Canopy Height and Area Index', Boundary-Layer Meteorol. 71, 211-216.

Raupach, M. R. and Finnigan, J. J.: 1997, 'The Influence of Topography on Meteorological Variables and Surface-Atmosphere Interactions', J. Hydrol. 190, 182-213.

Raupach, M. R. and Shaw, R. H.: 1982, 'Averaging Procedures for Flow within Vegetation Canopies', Boundary-Layer Meteorol. 22, 79-90.

Raupach, M. R., Finnigan, J. J., and Brunet, Y.: 1996, 'Coherent Eddies and Turbulence in Vegetation Canopies: The Mixing-Layer Analogy', Boundary-Layer Meteorol. 78, 351-382.

Raupach, M. R., Weng, S., Carruthers, D., and Hunt, J. C. R.: 1992, 'Temperature and Humidity Fields and Fluxes over Low Hills', Quart. Roy. Meteorol. Soc. 118, 191-225.

Sanz, C.: 2003, 'A Note on K-Epsilon Modelling of Vegetation Canopy Air-Flow', BoundaryLayer Meteorol. 108, 191-197.

Schulze, E. D., Lloyd, J., Kelliher, J., Wirth, C., Rebmann, C., Luhker, B., Mund, M., Knohl, A., Milyukova, I. M., Schulze, W., Ziegler, W., Varlagin, A. B., Sogachev, A. F., Valentini, R., Dore, S., Grigoriev, S., Kolle, O., Panfyorov, M. I., Tchebakova, N., and Vygodskaya, N. N.: 1999, 'Productivity of Forests in the Eurosiberian Boreal Region and their Potential to Act as a Carbon Sink - A Synthesis', Global Change Biol. 5, 703-722.

Siqueira, M. and Katul, G. G.: 2002, 'Estimating Heat Sources and Fluxes in Thermally Stratified Canopy Flows Using Higher-Order Closure Models', Boundary-Layer Meteorol. 103, 125-142.

Speziale, C. G.: 1996, 'Modeling of Turbulent Transport Equations', in J. Lumley (ed.), Simulation and Modeling of Turbulent Flows, Oxford University Press, New York, pp. 185242

Stull, R.: 1988, An Introduction to Boundary Layer Meteorology, Kluwer Academic Publishers, Boston, $666 \mathrm{pp}$.

Tennekes, H. and Lumley, J. L.: 1972, A First Course in Turbulence, Massachusetts Institute of Technology, Boston, 300 pp.

Warsi, Z. U. A.: 1992, Fluid Dynamics: Theoretical and Computational Approaches, CRC Press, London, 683 pp.

Wilson, J. D.: 1988, 'A 2nd-Order Closure Model for Flow through Vegetation', BoundaryLayer Meteorol. 42, 371-392.

Wilson, J. D., Finnigan, J. J., and Raupach, M. R.: 1998, 'A First-Order Closure for Disturbed Plant-Canopy Flows, and its Application to Winds in a Canopy on a Ridge'. Quart. J. Roy. Meteorol. Soc. 124, 705-732.

Wilson, J. D., Ward, D. P., Thurtell, G. W., and Kidd, G. E.: 1982, 'Statistics of Atmospheric Turbulence within and above a Corn Canopy', Boundary-Layer Meteorol. 24, 495-519.

Wilson, N. R. and Shaw, R. H.: 1977, 'A Higher Order Closure Model for Canopy Flows', $J$. Appl. Meteorol. 16, 1197-1205. 